\title{
THE DEBATE ABOUT THE SOURCES OF GROWTH IN EAST ASIA AFTER A QUARTER OF A CENTURY: MUCH ADO ABOUT NOTHING
}

Jesus Felipe and John McCombie

NO. 512

May 2017
ADB ECONOMICS WORKING PAPER SERIES 


\section{ADB Economics Working Paper Series}

\section{The Debate about the Sources of Growth in East Asia after a Quarter of a Century: much ado about nothing}

Jesus Felipe and John McCombie

No. 512 | May 2017
Jesus Felipe (jfelipe@adb.org) is advisor at the Economic Research and Regional Cooperation Department of the Asian Development Bank. John McCombie (jslm2@cam.ac.uk) is professor at the University of Cambridge.

We are grateful to the participants at an Asian Development Bank seminar, and to Tyler Cowen, Klaus Desmet, Enrique Feás, Neil Foster, Ricardo Hausmann, Carsten Holz, Lant Pritchett, Peter Robertson, Yasu Sawada, and Norio Usui for their comments and suggestions. The usual disclaimer applies. 
(C) (1)

(C) 2017 Asian Development Bank

6 ADB Avenue, Mandaluyong City, 1550 Metro Manila, Philippines

Tel +632632 4444; Fax +6326362444

www.adb.org

Some rights reserved. Published in 2017.

ISSN 2313-6537 (Print), 2313-6545 (e-ISSN)

Publication Stock No. WPS178815-2

DOI: http://dx.doi.org/10.22617/WPS178815-2

The views expressed in this publication are those of the authors and do not necessarily reflect the views and policies of the Asian Development Bank (ADB) or its Board of Governors or the governments they represent.

ADB does not guarantee the accuracy of the data included in this publication and accepts no responsibility for any consequence of their use. The mention of specific companies or products of manufacturers does not imply that they are endorsed or recommended by ADB in preference to others of a similar nature that are not mentioned.

By making any designation of or reference to a particular territory or geographic area, or by using the term "country" in this document, $A D B$ does not intend to make any judgments as to the legal or other status of any territory or area.

This work is available under the Creative Commons Attribution 3.0 IGO license (CC BY 3.0 IGO)

https://creativecommons.org/licenses/by/3.0/igo/. By using the content of this publication, you agree to be bound by the terms of this license. For attribution, translations, adaptations, and permissions, please read the provisions and terms of use at https://www.adb.org/terms-use\#openaccess

This CC license does not apply to non-ADB copyright materials in this publication. If the material is attributed to another source, please contact the copyright owner or publisher of that source for permission to reproduce it. ADB cannot be held liable for any claims that arise as a result of your use of the material.

Please contact pubsmarketing@adb.org if you have questions or comments with respect to content, or if you wish to obtain copyright permission for your intended use that does not fall within these terms, or for permission to use the ADB logo.

Notes:

1. In this publication, "\$” refers to US dollars.

2. ADB recognizes "China" as the People's Republic of China and "Hong Kong” as Hong Kong, China.

3. Corrigenda to ADB publications may be found at http://www.adb.org/publications/corrigenda 


\section{CONTENTS}

TABLES

ABSTRACT V v

$\begin{array}{ll}\text { I. INTRODUCTION } & 1\end{array}$

II. THE ORIGINAL WORK ON TOTAL FACTOR PRODUCTIVITY GROWTH
IN EAST ASIA

III. WHAT SHOULD WE MAKE OF EAST ASIA'S GROWTH ACCOUNTING
EXERCISES AND PRODUCTION FUNCTION ESTIMATIONS?

IV. A RECONSIDERATION OF THE DEBATES ABOUT PRODUCTIVITY GROWTH IN EAST ASIA FROM THE ACCOUTING IDENTITY CRITIQUE

V. WHAT LIES UNDER THE ACCOUNTING IDENTITY PROBLEM? 24

VI. $\quad$ CONCLUSIONS: WHAT DID WE LEARN FROM (AND WHAT IS LEFT OF) THE DEBATES ABOUT THE SOURCES GROWTH IN EAST ASIA? 26

$\begin{array}{ll}\text { APPENDIX } & 29\end{array}$

$\begin{array}{ll}\text { REFERENCES } & 31\end{array}$ 


\section{TABLES}

1 Growth Accounting for the East Asian NIEs

2 Growth Accounting for Singapore; Hong Kong, China; Republic of Korea; and Taipei,China: Dual and Primal Estimates

3 Definition of Variables 


\begin{abstract}
This paper reviews what the profession has learned during the last 25 years about East Asia's growth using growth accounting exercises and estimations of production functions. The publication of Alwyn Young's (1992, 1994, 1995) and Jong-II Kim and Lawrence Lau's (1994) studies, and Paul Krugman's (1994) popularization of the "zero total factor productivity growth" thesis, led to a very important debate within the profession. The paper demystifies this literature by pointing out a major methodological problem inherent in these approaches. This is that the variables used, namely, output, employment, the stock of capital, and the factor shares, are related definitionally through an accounting identity in value terms. As a consequence, results that are believed to reflect a true technological or production relationship are no more than the outcome of manipulating this identity. We show that total factor productivity calculated with value data is not a measure of productivity. We conclude that the debate about the sources of growth in East Asia was much ado about nothing.
\end{abstract}

Keywords: accounting identity, dual TFP, East Asia, growth accounting, primal TFP, technical progress

JEL codes: $010,047,053$ 
"Popular enthusiasm about Asia's boom deserves some cold water thrown on it. Rapid Asian growth is less of a model for the West than many writers claim and the future prospects for that growth are more limited than

almost anyone now imagines."

Paul Krugman (1994, p.64)

"In a sense, the total factor productivity debate is much ado about nothing"

Joseph Stiglitz (2001, p.512)

\section{INTRODUCTION}

The year 2017 marks the 25th anniversary of an important paper in the areas of growth and development. This was the paper by Alwyn Young (1992) entitled A Tale of Two Cities: Factor Accumulation and Technical Change in Hong Kong and Singapore. Young performed a growth accounting exercise for these two very small economies using data for 1965-1990, the results of which, at the time, seemed to have very important implications for our understanding of Asia's development. He found that while multifactor or total factor productivity (TFP) growth in Hong Kong, China had been marginally positive during the period in question, it had been zero in Singapore, i.e., all growth was due to factor accumulation, especially capital.

Krugman (1994) popularized this result in his much discussed article The Myth of Asia's Miracle. He argued that East Asia's spectacular growth during 1965-1990 had been similar in nature to that of the Soviet Union during the 1950s and 1960s and, for this reason, it would meet the same fate, namely stagnation, unless innovation took over as a driver of growth. Young $(1994,1995)$ extended his original work to include the Republic of Korea and Taipei,China. The conclusion remained intact: most growth in the Newly Industrialized Economies (NIEs) had come from factor accumulation, especially capital. Young's papers led to an intense debate in academia and policy circles for years (see Felipe 1999 for a survey).

Young's results and Krugman's interpretation of the miracle set in motion a debate over issues of measurement and the size of TFP growth. Empirical papers on East Asia's growth have one important commonality. This is that most of them analyzed growth through the lens of the neoclassical model of Solow (1956) and, in particular, Solow (1957) - the year 2017 marks the 60th anniversary of the latter. Indeed, most of these authors performed growth accounting exercises (a few estimated the production function) with a view to apportioning overall growth between that due to factor accumulation and that due to TFP growth.

This is a critical paper in its approach and conclusions. It surveys the East Asian debate by discussing the methodology that underlies all the empirical estimates. ${ }^{1}$ Our view is that to grasp this literature and the debates it engendered, it is necessary to understand how the notion of productivity and technical progress it refers to is calculated. The standard approach in economics is to improve upon

1 We note that, parallel to this work, there was a literature on the People's Republic of China (PRC), e.g., Chow (1993). It used the same methods as the literature we discuss here and also reached the conclusion that TFP growth had been zero between the 1950s and 1980s. These results were not questioned because they appeared to concur with scholars' intuition about the PRC, i.e., lack of productivity. We do not discuss it due to lack of space. Suffice to say that it suffers from the same problems we discuss here. See Felipe and McCombie (2011). 
and develop previous work. Methodological criticisms that question the status quo or prevailing paradigms are simply ignored. We believe, however, there is nothing to improve here: the growth accounting and aggregate production function estimation approaches are a dead end because they ask the wrong question, which they try to answer with the wrong data, and because the model that underlies these approaches can never be refuted empirically.

The rest of the paper is structured as follows. Section II provides a summary of the original work on the sources of growth in East Asia, which focused on Hong Kong, China; Singapore; the Republic of Korea; and Taipei,China (i.e., the so-called NIEs). Our discussion in sections III and IV aims at demystifying these debates by pointing a fundamental problem of this literature, namely, that the series of output and capital (both constant-price value data), and of labor used to estimate the production function or to undertake growth accounting exercises, are related through an accounting identity. This is not a new criticism: Herbert Simon (1979a) used it to question estimates of production functions and thought that it was sufficiently important so as to mention it in his Nobel Prize lecture (Simon 1979b, p.497). However, it has generally been ignored in the literature. We extend it and show how this problem questions and invalidates East Asia's growth analyses and their implications. In particular, we show that total factor productivity calculated with value data is not a measure of productivity. Paradoxically, this accounting identity was proposed by Barro $(1999)$ and Hsieh $(1999,2002)$ as a framework to undertake growth accounting. We develop our arguments by discussing a series of well-known examples in this debate: Young (1992, 1994, 1995); Hsieh (1999, 2002); Wong and Gan (1994); Kim and Lau (1994); Nelson and Pack (1999).

Section $V$ elaborates on the difference between using constant-price value data and the theoretically correct physical quantities to estimate production functions. Section VI offers some concluding remarks. Our view is that the reason why this literature became well known was the finding of very small TFP growth rates for countries where intuition called for the opposite. We question, however, the relevance of the discussion of East Asia's growth in terms of factor accumulation versus TFP growth, on the grounds that all exercises used constant-price value data related through an identity. Consequently, and from a logical point of view, we conclude that we did not learn anything from these exercises. The growth literature has to move beyond the framework of the neoclassical model.

\section{THE ORIGINAL WORK ON TOTAL FACTOR PRODUCTIVITY GROWTH IN EAST ASIA}

The 1990s witnessed perhaps one of the most important debates in the history of growth and development. This was the debate of the sources of growth in East Asia. The key aspect of this debate was that it was empirical and had very important policy implications. In the early 1990 s, when the success of the East Asian economies was an open secret, it was of paramount importance for development economists and policy makers to understand how the East Asian economies had achieved such phenomenal growth rates for 3 decades, which led to large increases in the living standards of their populations.

Both economists and noneconomists became familiar with Krugman's (1994) gloomy assessment of East Asia's miracle, based on Young's (1992, 1994, 1995) empirical work. As the region's initial rapid growth was predominantly due to capital accumulation, stagnation would eventually occur because of diminishing returns, in much the same way as it had occurred in the Soviet Union. For this reason, it is important to review this debate with the perspective of time, and evaluate how much the 
profession has learned from it. This matters because the literature on East Asia's growth of the 1990s was profoundly influenced by Young's controversial findings. Many researchers still use the neoclassical growth framework, and, as a consequence, most discussions about growth are still today framed in terms of factor accumulation versus TFP growth, often interpreted as measuring the rate of technical progress.

Young (1992) conducted a very careful study on what is known in the literature as the analysis of the sources of growth or growth accounting, based on the single-sector neoclassical growth model, and compared the performance of Singapore with that of Hong Kong, China during 1965-1990. This exercise has its origins in the neoclassical growth model, where output produced is assumed to be a function of the inputs used, labor and capital, and of technology (Solow 1956), and in particular on Solow's (1957) growth accounting exercise. This methodology starts from an aggregate production function $Q_{t}=A_{t} F\left(K_{t}, L_{t}\right)$, where $Q$ is the deflated value of aggregate output, $K$ is the deflated value of aggregate stock of capital, $L$ is employment, and $A$ is the level of technology or total factor productivity (TFP), assumed, in this case, to be Hicks neutral (i.e., technical progress that leaves the ratio of the marginal products unchanged). As Van Beveren (2012, p.100) quite correctly notes, the three series in the production function should be measured in physical units. Indeed, Cobb and Douglas (1928, pp.13940), in their seminal article, refer explicitly to "physical product" and "the physical quantity of (1) machinery, tools, and equipment and (2) factory buildings." Sections IV and V delve on this issue.

However, in practice, researchers use value data (e.g., dollars, pounds) or indices for aggregate output and capital because at any level of aggregation there are no physical quantities but their values (output and capital of the oil, automobile, health, and banking sectors), and even at the enterprise level, researchers use also value data. The use of value data is a point of utmost importance, the key aspect of our discussion. This is because a production function is a relationship among physical quantities (e.g., number of cars, widgets [output]; number of computers, square meters of office space, kilograms of steel etc. [inputs]). This is a fact neglected in the literature. As we shall see below, it has great consequences. The essentials of the sources of growth framework are so well known and accepted that it may seem redundant to review them. On the other hand, since the theme of this article is the inadequacy of this framework, it is probably best to have it before us.

By totally differentiating the production function with respect to time, the growth rate of output is $\hat{Q}_{t}=\widehat{T F P}_{t}+\alpha_{t} \hat{L}_{t}+\beta_{t} \hat{K}_{t}$, where $\hat{Q}_{t}$ is the growth rate of output; $\hat{L}_{t}$ is the growth rate of labor; $\hat{K}_{t}$ is the growth rate of the capital stock; $\alpha_{t}$ and $\beta_{t}$ denote the elasticities of output with respect to labor and capital, respectively; and $\widehat{T F P}$ denotes the rate of technological progress (i.e., the growth rate of $A_{t}$ ), which is referred to as total factor productivity growth, a variable that captures all output growth not due to increases in factor inputs. The objective of growth accounting is to obtain an estimate of $\widehat{T F P}_{t}$ residually as $\widehat{T F P}=\hat{Q}_{t}-\alpha_{t} \hat{L}_{t}-\beta_{t} \hat{K}_{t}$, given values for the right-hand side variables. The problem, however, is that there are very few reliable estimates of the elasticities. To solve this inconvenience, growth accounting exercises assume that: (i) production is subject to constant returns to scale, (ii) the objective function of the firms in the economy is to maximize profits, and (iii) labor and capital markets are perfectly competitive (the first-order optimizing conditions). Under these circumstances, the factor elasticities equal the shares of labor and capital in total output, i.e., $\alpha_{t}=a_{t}$ and $\beta_{t}=\left(1-a_{t}\right)$, where $a_{t}$ and $\left(1-a_{t}\right)$ denote the labor and capital shares in output, respectively. Then output growth can be written as: 


$$
\hat{Q}_{t}=\widehat{T F P}_{t}+a_{t} \hat{L}_{t}+\left(1-a_{t}\right) \hat{K}_{t}
$$

and the growth rate of TFP is calculated as:

$$
\widehat{T F P}=\hat{Q}_{t}-a_{t} \hat{L}_{t}-\left(1-a_{t}\right) \hat{K}_{t}
$$

given that data for all the right-hand side variables are now readily available (the shares of labor and capital in total output can be obtained from the national accounts). The residually measured TFP growth in equation (2) is taken to provide an estimate of that part of output growth not explained by the growth of labor and the growth of capital. It is referred to as the primal measure of TFP growth. In practice, Young derived equation (2) assuming a translog production function and the Tornqvist approximation, which requires the use of the average factor shares at the start and end periods, e.g., $\bar{a}=\left(a_{0}+a_{T}\right) / 2$.

Note that equation (2) is a truism. In other words, the estimate of TFP growth is definitionally true and the equation is used to apportion growth. However, it is based on an underlying theoretical model in that the output elasticities are assumed to be equal to the relevant factor shares. There is nothing in neoclassical production function theory that says that this has to be the case, i.e., one could potentially refute this assumption empirically. ${ }^{2}$ The fact that most authors today do not test these assumptions prior to undertaking a growth accounting exercise does not mean that they are not important.

The econometric estimation of the production function is a second method to obtain an estimate of the rate of TFP. The most simple case consists in estimating the Cobb-Douglas form $Q_{t}=A \exp (\hat{\lambda} t) L_{t}^{\alpha} K_{t}^{\beta} \exp \left(u_{t}\right)$, or in growth rates as $\hat{Q}_{t}=\hat{\lambda}+\alpha \hat{L}_{t}+\beta \hat{K}_{t}+u_{t}$, where $\hat{\lambda}$ is the (constant) rate of TFP, although it need not be constant and, as we shall see below, other functional forms can be estimated (e.g., translog). This method does not impose the assumption of perfectly competitive markets, i.e., the coefficients (factor elasticities) are estimated unrestricted. Barro (1999), however, claimed that the estimation of the production function is problematic as a method to calculate the rate of technical progress, hence the comment above that there are few reliable estimates of the elasticities and the profession's preference for the growth accounting procedure. ${ }^{3}$ We shall see below that Barro's concerns are misplaced.

Finally, the growth rate of TFP can also be calculated through the cost function $C_{t}=\left(\Omega_{t}, Q_{t}, t\right)$, where $\Omega$ denotes the vector of factor prices, that is, the wage rate $(w)$ and the rental price of capital ( $\rho$ ). Technical progress here is equated with the rate of cost diminution, where the idea is that technical

2 This is something that Paul Douglas and his associates did in the 1930s. It can be done by positing and estimating a particular form of the production function in growth rate form $\hat{Q}_{t}=\widehat{T F P}_{t}+\alpha_{t} \hat{L}_{t}+\beta_{t} \hat{K}_{t}+u_{t}$, for example a Cobb-Douglas, i.e., $\hat{Q}_{t}=\hat{\lambda}+\alpha \hat{L}_{t}+\beta \hat{K}_{t}+u_{t}$, where $\hat{\lambda}$ measures the constant rate of TFP growth, and where the coefficients $\alpha$ and $\beta$ are estimated unrestricted. Then one can test the null hypothesis that the elasticities equal the actual factor shares, i.e., $H_{0}: \alpha=a$ and $\beta=(1-a)$. Obviously, these coefficients need not be constant so one can use any form (such as the constant elasticity of substitution or translog production functions) and statistical procedure.

3 He listed the following three problems: (i) the growth rates of capital and labor are not exogenous variables with respect to the growth of output; (ii) the growth of capital is usually measured with errors, which often leads to low estimates of the contribution of capital accumulation; and (iii) the regression framework must be extended to allow for variations in factor shares and the TFP growth rate. 
progress lowers the cost of obtaining a given output. It is referred to as the dual measure of TFP growth. The cost function can also be used in a growth accounting exercise, or can be estimated econometrically. The dual is simply calculated by equating the rate of change in product prices with the rate of change in unit costs, and equals:

$$
\widehat{T F P}_{t}^{D}=\vartheta_{L t} \hat{w}_{t}+\vartheta_{K t} \hat{\rho}_{t}
$$

that is, a weighted average of the growth rates of the wage rate and of the rental rate of capital, where the weights $\vartheta_{i t}$ are the respective cost shares. We will see below in section IV how the dual was derived by Hsieh $(1999,2002)$, who found higher TFP growth (especially for Singapore) than Young.

As noted above, Young (1992) found the surprising result that while for Hong Kong, China, TFP growth was relatively sizeable, namely, around a third of output growth, it was negligible for Singapore. Growth in the latter had been largely the result of capital accumulation. How did Young justify his findings? He argued that freedom of markets in Hong Kong, China was at the back of the result. Singapore, on the other hand, had been victim of its industrial policies and state intervention, which led it to move into the production of sophisticated goods and services industries before it had acquired the necessary capabilities.

Young (1994), instead of imposing the factor shares and undertaking a growth accounting exercise, estimated econometrically a growth regression by imposing the constraint that the factor shares add up to unity. The results were virtually identical to those with growth accounting. Young (1995) extended his growth accounting analysis and included the Republic of Korea and Taipei,China. Overall, he concluded that there was nothing miraculous about these economies' performance. Singapore's TFP growth was again zero. For Hong Kong, China; the Republic of Korea; and Taipei,China, it had been positive, but not spectacular when put in an international context. Capital accumulation had been the essence of their growth strategy. Table 1 summarizes Young (1995) results and Table 2 those of Hsieh (2002).

Table 1: Growth Accounting for the East Asian NIEs

\begin{tabular}{l|c|c|c|c}
\hline & $\begin{array}{c}\text { Output } \\
\text { Growth } \\
(\%)\end{array}$ & $\begin{array}{c}\text { Contribution of } \\
\text { Capital Growth } \\
(\%)\end{array}$ & $\begin{array}{c}\text { Contribution of } \\
\text { Labor Growth } \\
(\%)\end{array}$ & $\begin{array}{c}\text { Contribution of } \\
\text { TFP Growth } \\
(\%)\end{array}$ \\
\hline $\begin{array}{l}\text { Republic of Korea } \\
(1966-1990)\end{array}$ & 10.3 & 4.1 & 4.5 & 1.7 \\
\hline $\begin{array}{l}\text { Taipei,China } \\
(1963-1990)\end{array}$ & 9.4 & 3.2 & 3.6 & 2.6 \\
\hline $\begin{array}{l}\text { Singapore } \\
(1966-1990)\end{array}$ & 8.7 & 5.6 & 2.9 & 0.2 \\
\hline $\begin{array}{l}\text { Hong Kong, China } \\
(1966-1991)\end{array}$ & 7.3 & 3.0 & 2.0 & 2.3 \\
\hline
\end{tabular}

NIEs = newly industrialized economies, TFP = total factor productivity .

Note: The contributions of weighted (translog indices of factor input growth, with labor services measured by hours of work) labor and capital are the products of each factor growth rate times the respective shares.

Source: Young (1995, Tables V, VI, VII, VIII). 
Table 2: Growth Accounting for Singapore; Hong Kong, China; Republic of Korea; and Taipei,China: Dual and Primal Estimates

\begin{tabular}{l|c|c}
\hline & $\begin{array}{c}\text { Annual Growth of } \\
\text { Dual TFP } \\
(\%)\end{array}$ & $\begin{array}{c}\text { Annual Growth of } \\
\text { Primal TFP } \\
(\%)\end{array}$ \\
\hline Republic of Korea & 1.86 & 1.70 \\
\hline Singapore & 1.76 & -0.52 \\
\hline Hong Kong, China & 2.34 & 2.26 \\
\hline Taipei,China & 3.70 & 2.62 \\
\hline
\end{tabular}

TFP = total factor productivity.

Note: Figures shown are averages of the different estimates provided by Hsieh using different interest rates. Periods vary around 1970-1990.

Source: Hsieh (2002, Table 1).

Young's papers were followed by that of Kim and Lau (1994), who estimated the production function with data for the four East Asian NIEs and for the G5 countries. Their methodology avoided the problem of imposing the seemingly restrictive assumptions of growth accounting. In fact, Kim and Lau (1994) tested those assumptions and rejected them. Their results were even more provocative than those of Young $(1992,1994,1995)$ for these authors concluded that productivity growth had been zero not only in Singapore, but also in the other three successful East Asian economies, namely, Hong Kong, China; the Republic of Korea; and Taipei,China. These authors also calculated the level of technology of the East Asian Tigers with respect to that of the United States (US) and concluded that in 1960 it was only around one-fifth. In 1990, it was still only around a quarter of that of the US.

These papers became widely known in academic circles and Young's (1992) paper was even featured in The Economist. It was in 1994 when the debate took a different dimension. Paul Krugman (1994) wrote a paper in Foreign Affairs, noted above, where he explained in layman's terms what the discussion was about. Few papers in the fields of (policy) growth and development have been as controversial as that of Paul Krugman. He argued that the East Asian Tigers' success during the previous 3 decades was no miracle, that it had been more the result of perspiration than of inspiration. Drawing upon Alwyn Young's (1992) and Kim and Lau's (1994) works, by this, Paul Krugman meant that growth in East Asia during 1965-1990 had been mostly the result of capital accumulation (perspiration), while efficiency or productivity gains (inspiration) had played a minimal role. ${ }^{4}$ This led Paul Krugman to compare the East Asian economies (and their growth model) to the Soviet Union, and to the prediction that growth rates in the region would have to decline as a result of the effects of diminishing returns to capital. ${ }^{5}$

Krugman's paper set off a "cyclone of protest" across the region. Singapore's government even announced that it would set up the goal of achieving a 2\% annual increase in TFP growth. The problem for some with the low-TFP growth results was that the conventional wisdom during the period of high growth of the East Asian economies was that much of their success had been largely due to

4 It is worth noting that Krugman, discussing Young's paper in 1992, questioned the results on the basis of measurement issues: "Singapore in particular has an import share well over 100\%, thanks to intermediate inputs. This means that measures of real output are essentially measures of real value added. Such measures are notoriously fickle, easily biased by problems of quality adjustment - and especially when there is rapid structural change. So one possible rationalization of the results is that in fact Singapore grew more rapidly than the numbers suggest" (Krugman 1992, p.55).

5 The East Asian financial crisis only a few years later seemed to prove him right, although Krugman explained that his arguments were unrelated to the factors that led to the crisis. 
technological catch-up and productivity gains. What was the role, otherwise, of all the influx of foreign direct investment? How was it that the accompanying foreign technology had not translated into productivity gains? If productivity growth was not there, what was there to be learned from the success of these economies?

\section{WHAT SHOULD WE MAKE OF EAST ASIA'S GROWTH ACCOUNTING EXERCISES AND PRODUCTION FUNCTION ESTIMATIONS?}

After the publication of the Young and Kim-Lau papers, there was a lively debate for a number of years on the accuracy of the estimates and on the validity of the inferences and implications for policy and development. The literature took two roads in evaluating the main results and conclusions of Young's and Kim and Lau's works. The first one was to accept their results and argue that, indeed, there was nothing miraculous in the way East Asia succeeded. Under this view, government savings and investment policies were a critical part of the miracle.

The second one was to argue that the residual had been measured incorrectly. Some authors came up with different sets of estimates to justify the opposite view, i.e., higher residual. This was done on countless occasions, but the truth is that any discussion about growth in the region still today starts from the old YoungKim-Lau results. Journals and books were flooded with alternative estimates of total factor productivity growth using different data series, and slightly different periods, to the point that the discussion, in these authors' view, became of limited, or of no, value. One positive aspect of this controversy was, nevertheless, the questioning of some of the assumptions made by Young, such as the existence of competitive markets in the region, in the face of overwhelming evidence to the contrary. Governments intervened, for example, in wage setting, as in Singapore (Stiglitz 2001, p.512). Many other voices, especially in East Asia, argued that the key to understanding the East Asian miracle resided in an understanding of how the economies in the region assimilated and incorporated foreign technology, and that the methodologies used by Young and Kim and Lau cannot shed any light on this (Rashid 2000, p.152).

All these issues were summarized and discussed by Felipe (1999), who offered an extensive review and discussion and warned researchers of what he termed the Solowresidualization of the East Asian economies in order to understand how they had grown, and appealed to the profession to abandon that research program, unless one had something truly novel to say. The recalculation of TFP growth rates was an exercise that, in general, would not produce new insights. ${ }^{6}$ Wong and Gan (1994) and Hsieh $(1999,2002)$ contributed to this debate by using the dual of TFP growth, which led them to higher estimates. Other authors who believed that the residual was higher argued that the region had seen substantial technical improvements in these economies and emphasized the need for theories that explained the sources of productivity growth (Nelson and Pack 1999, Robertson 2000). ${ }^{7}$

6 Felipe (1999) provided a comprehensive survey of the many estimates of TFP growth for the East Asian economies produced since 1992. Authors used different databases on output and inputs; introduced human capital in the production function; and applied different factor shares from those Young had used (and set them constant across time on the assumption of a Cobb-Douglas production function, and equal across countries). However, the rationale provided for doing this was more than questionable. See Fischer (1993), Collins and Bosworth (1997), and Klenow and Rodríguez-Clare (1997) for examples of fixing the shares for a large sample of countries.

7 Robertson (2000) calibrated a neoclassical growth model. The problem was that this model could not generate the data presented by Alwyn Young. With so little TFP growth, there could not be such large capital accumulation, even given increases in the investment rate. Robertson showed that productivity growth was very important. The intuition behind his results was that productivity growth induces capital accumulation. Hence, part of the growth of capital stock can be attributed to productivity growth. 
We believe there is a third option. This is not to question the numbers per se, and whether estimated TFP growth was too low, but the methodology used. We have always considered that this was the most useful way to understand the discussion with a view to moving forward. This is what we do in the rest of this section and in the following.

\section{The Accounting Identity Critique: A Matter of Logic}

To motivate the reasoning that underlies our case, we note that Barro (1999) and Hsieh $(1999,2002)$ argued that growth accounting can be performed directly from the accounting identity that relates factor payments to gross domestic product (GDP). To understand their reasoning, we start by writing this identity as the data appear in the National Income and Product Accounts (NIPA):

$$
Q_{t}^{n} \equiv W_{t}^{n}+O S_{t}^{n}
$$

where $Q_{t}^{n}$ is nominal value added (e.g., dollars); $W^{n}$ is the nominal wage bill (dollars); and $O S^{n}$ is total nominal operating surplus (dollars). It is very important to stress that this identity (note the symbol $\equiv$ ), at the aggregate level of the economy, is in value terms. NIPA statisticians construct it by arithmetic aggregation from firm-level data. It is theory free (e.g., it does not depend on the zero profits assumption). This relationship can also be expressed in real terms as $Q_{t} \equiv W_{t}+O S_{t}$, with the variables appropriately deflated.

Next, and this is key to the Barro-Hsieh's arguments, the idea is to split both the wage bill and the operating surplus into the product of a price times a quantity, maintaining the units of the product, that is, dollars. This may look simple, but it is not. In the case of the wage bill, the price is the average nominal wage rate $w^{n}$ (dollars per worker) and the quantity is total employment $L$ (number of workers), that is, $W^{n}=w^{n} L$. Splitting the operating surplus is conceptually much more challenging as we shall see in section IV. We follow the convention and split it into an ex post average profit rate $r^{n}$ (dollars of surplus per dollar of capital stock, a pure number, percent) times the stock of capital $K$ (dollars of a base year), that is, $O S^{n}=r^{n} K$. The stock of capital is most often calculated using the perpetual inventory method. The identity now becomes:

$$
Q_{t}^{n} \equiv W_{t}^{n}+O S_{t}^{n} \equiv w_{t}^{n} L_{t}+r_{t}^{n} K_{t}
$$

We refer to $r^{n}$ as an ex post profit rate because of how it is calculated, residually using data for the other variables as $r^{n}=\left(Q_{t}^{n}-W_{t}^{n}\right) / K_{t}$. Identity (5) can also be expressed in real terms as $Q_{t} \equiv W_{t}+O S_{t} \equiv w_{t} L_{t}+r_{t} K_{t}$, where $Q=\left(Q^{n} / P\right)$ is expressed in dollars of a base year, the wage rate appropriately deflated, and $r=\left(Q_{t}-W_{t}\right) / K_{t}$. Equation (5) also involves arithmetic aggregation. In anticipation of our critique, we note that the series of deflated output $(Q)$, employment $(L)$, and deflated capital stock $(K)$ in the identity are the same as those in the production function. The implications of this seemingly trivial point seem not to have been appreciated. We will see in section IV that Hsieh's identity is slightly different from (5). This does not affect the arguments.

Incidentally, equation (5) is the same identity that Simon (1979a) used to question estimates of production functions. As we shall show, the critique logically applies equally to growth accounting exercises. Despite this, and somewhat surprisingly, Barro (1999, p.123) noted that: "the dual approach 
can be derived readily from the equality between output and factor income." He continued: "it is important to recognize that the derivation of equation (8) [the growth accounting equation in Barro's paper] uses only the condition $Q_{t} \equiv w_{t} L_{t}+r_{t} K_{t}$. No assumptions were made about the relations of factor prices to social marginal products or about the form of the production function" (Barro 1999, p.123). And: "If the condition $Q_{t} \equiv w_{t} L_{t}+r_{t} K_{t}$ holds, then the primal and dual estimates of TFP growth inevitably coincide [...] If the condition $Q_{t} \equiv w_{t} L_{t}+r_{t} K_{t}$ holds, then the discrepancy between the primal and dual estimates of TFP has to reflect the use of different data in the two calculations" (Barro 1999, p.123-24). ${ }^{8}$ To show this, he writes the income accounting identity, differentiates it, and expresses it in terms of growth rates (Barro 1999, equations [7] and [8], p. 123). Hsieh (2002, p.505) concurs that "with only the condition that output equals factor incomes, we have the result that the primal and dual measures of the Solow residual are equal. No other assumptions are needed for this result: we do not need any assumption about the form of the production function, bias of technological change, or relationship between factor prices and their social marginal products."

Following these two authors, one simply has to express the income accounting identity (5) in real terms expressed in growth rates as $\hat{Q}_{t} \equiv a_{t} \hat{w}_{t}+\left(1-a_{t}\right) \hat{r}_{t}+a_{t} \hat{L}_{t}+\left(1-a_{t}\right) \hat{K}_{t}$, where $a_{t}$ and $\left(1-a_{t}\right)$ are the labor and capital shares in GDP, to simultaneously obtain the primal and dual growth rates of TFP:

$$
\widehat{T F P}_{t}^{1} \equiv \hat{Q}_{t}-a_{t} \hat{L}_{t}-\left(1-a_{t}\right) \hat{K}_{t} \equiv a_{t} \hat{w}_{t}+\left(1-a_{t}\right) \hat{r}_{t} \equiv \widehat{T F P}_{t}^{D 1}
$$

Indeed, it appears that left- and right-hand sides of equation (6) look like equations (2) and (3), respectively (the latter with a difference that we will address in section IV, Example 1). This seems to be a very ingenious proposal and one is tempted to conclude that it shows that primal and dual TFP growth can be derived from the accounting identity. This is incorrect, however, although it is true that equations (2) and (6) will give the same numerical result. The view, however, that primal and dual of TFP growth can be derived from an income accounting identity suffers from three interrelated methodological problems.

First, it is important to note that if it were true that the growth accounting equation can be derived and interpreted as Barro and Hsieh proposed, how could one discuss Young and Krugman's arguments about decreasing returns to capital accumulation (and more generally, the degree or returns to scale), with an accounting identity? Indeed, while arguing that the growth accounting equation can be derived from the accounting identity, Hsieh reasoned as if his results had been derived from the neoclassical production and cost functions. For example, the justification for using factor shares as weights for the growth of the factor inputs rests on the argument that they are a good approximation to the output elasticities. However, this requires standard neoclassical production/cost theory.

Second, the Barro-Hsieh derivation does not come from a model that can be tested and potentially refuted. It is true that the left-hand side of expression (6) looks like that derived from the production function, equation (2); and that right-hand side of expression (6) looks like that derived from the cost function, equation (3). The problem is that, as we argued above, the standard growth accounting equation (2), upon which Young's work was based, comes from the neoclassical theory of production, and was derived under the assumptions of perfectly competitive factor markets and constant returns to scale, which one should be able to test, although this is not done by growth

8 The notation in the quotations has been changed to make it consistent with that in this paper. 
accountants. And the same applies to equation (3). However, no assumption is made to derive equation (6) and no data set can refute it.

This last point takes us to the third problem of this literature. The arguments above do not mean that what Young and others did is correct because they derived the growth accounting equation from the production function (or, like Kim and Lau, estimated it), and not from the identity. The reason why equation (2) is identical to equation (6) is that the series used in both are the same, and are linked through the value-added identities (4)-(5).

What do these problems mean for empirical work? Note that one can write the accounting identity equation (6) as $\hat{Q}_{t} \equiv \hat{\lambda}_{t}+a_{t} \hat{L}_{t}+\left(1-a_{t}\right) \hat{K}_{t}$ where $\hat{\lambda}_{t} \equiv a_{t} \hat{w}_{t}+\left(1-a_{t}\right) \hat{r}_{t}$. Now recall the production function in growth rate form, $\hat{Q}_{t}=\widehat{T F P}_{t}+\alpha_{t} \hat{L}_{t}+\beta_{t} \hat{K}_{t}$. It is supposed to be a model that could be estimated as $\hat{Q}_{t}=\hat{\varphi}_{t}+\alpha_{t} \hat{L}_{t}+\beta_{t} \hat{K}_{t}+u_{t}$. By comparing this regression and equation (6), it should be obvious that the only possible result is $\alpha_{t} \equiv a_{t}, \beta_{t} \equiv\left(1-a_{t}\right)$, and $\hat{\varphi}_{t} \equiv \hat{\lambda}_{t} \equiv a_{t} \hat{w}_{t}+\left(1-a_{t}\right) \hat{r}_{t}$, with a perfect fit, unless one decides to assume, for example, that $\alpha_{t}, \beta_{t}$, and $\hat{\varphi}_{t}$ are constant when they are not. Under these circumstances, the fact that the statistical fit may not be perfect could lead to the misapprehension that a model (with a stochastic error term) is being estimated. This simply misunderstands the underlying logic. Note also that any estimation method that picks up the variation in the factor shares and in $\hat{\lambda}_{t}$ (e.g., a time-varying parameter methodology), should show that what is being estimated is the identity. Naturally, the finding that $\alpha_{t} \equiv a_{t}$ and $\beta_{t} \equiv\left(1-a_{t}\right)$ would seem to imply constant returns to scale and that factor markets are perfectly competitive. These results do not mean, however, that the world is one of constant returns to scale and perfectly competitive markets. They are the result of the accounting identity, which prevents any other result. The upshot of this discussion is that this approach is very problematic for the literature on endogenous growth, increasing returns to scale, and imperfect markets. The latter might exist but this method will always reject these hypotheses (once again, if the regression is estimated correctly). Finally, all this also implies that there are no estimation problems as discussed in the literature, e.g., regressors' endogeneity that call for instrumental variable estimation (see Van Beveren 2012). This discussion proves that Barro's (1999) concerns about the estimation of production functions do not pose any problem, although for reasons unrelated to his arguments. The Appendix at the end of the paper elaborates on the implications of this argument.

\section{The Aggregation Problem: Aggregate Technology?}

The arguments above about the accounting identity and the use of value data are reinforced by the wellknown but ignored aggregation problems in production functions, i.e., that the conditions to aggregate microproduction functions into an aggregate production function with neoclassical properties are extremely stringent. This result has been known since the 1940s (when Klein, Leontief and Nataf, started asking whether and how microproduction functions could be aggregated) and, very clearly, since the 1960s, as a result of the work of Franklin Fisher and others (see Felipe and Fisher 2003 for a discussion). It is puzzling that such well-established finding has been ignored in all this debate. Felipe and Fisher (2003) reviewed and discussed the very well-established literature on aggregation in production functions and reminded the profession that the conditions under which aggregate production functions with neoclassical properties exist, in the sense that they can be generated from microproduction 
functions, are so stringent that they are not met by actual economies. ${ }^{9}$ Recently, Wilson (2009) has provided evidence that this is indeed the case. What all this means is that the representation of an economy as $Q=F(K, L)$ is incorrect. It is very difficult to understand all the modern literature on TFP growth when, as far back as 1970, Nadiri, in a survey on the topic, already claimed that the aggregation problem matters because "without proper aggregation we cannot interpret the properties of an aggregate production function, which rules the behaviour of total factor productivity" (Nadiri 1970, p.1144). ${ }^{10}$

The conclusion is that the TFP growth research program asks the wrong question: if one has doubts about the legitimacy of an aggregate production function, it does not make sense to talk about technical progress in aggregate terms, at the economywide level. Actual technical change occurs at the level of the individual productive process. All we know is that the various industries are linked by their use of inputs produced by all of them, but this does not mean that the idea of the growth rate of aggregate technology is meaningful.

\section{A RECONSIDERATION OF THE DEBATES ABOUT PRODUCTIVITY GROWTH IN EAST ASIA FROM THE ACCOUTING IDENTITY CRITIQUE}

To appreciate the damaging implications of the accounting identity argument for the literature on the East Asian debate, we review the some of the best well known articles through the prism of the critique. We start with Hsieh $(1999,2002)$ and Young $(1992,1994,1995)$, and then revisit the work of Wong and Gan (1994), Kim and Lau (1994), and Nelson and Pack (1999). In a nutshell, we will show that all these exercises do is to manipulate in different ways the accounting identity (5) and in growth rates equation (6), or variants of them. The reader will appreciate that, ultimately, the problems we expose in all cases are a matter of logic, whether the authors work directly with the accounting identity (Hsieh), derive the growth accounting regression from the production (or cost) function (Young), or estimate the latter econometrically (Kim and Lau). The use of constant-price value data invalidates these exercises. Since in what follows we discuss identities (5)-(6) rewritten in different ways, in particular differentiating between true physical quantities and values (either in nominal, or real terms, i.e., deflated), we summarize in Table 3 the notation we use.

9 This is not the place to go in detail over the aggregation conditions. Suffice to say that Fisher approached the issue for the first time in the mid-1960s by asking how to aggregate the production functions of individual firms when markets allocate factors of production so that aggregate production is efficient. When can this be represented by an aggregate production function? The efficiency condition is very important for without it the literature had already shown that aggregation was virtually impossible. Fisher showed that even under this condition, aggregation was virtually impossible. It can be done in some very restrictive circumstances, such as when relative prices remain constant, relative quantities remain constant, every firm has the same constant-returns-to-scale production function, or there is only one kind of capital, one kind of labor, and one kind of output to begin with-and all are allocated to firms to achieve efficiency. Even under constant returns, the conditions for aggregation are so very stringent as to make the existence of aggregate production functions in real economies a nonevent. See Felipe and Fisher (2003).

10 It is worth quoting Nadiri on this: "The conclusion to be drawn from this brief discussion is that aggregation is a serious problem affecting the magnitude, the stability, and the dynamic changes of total factor productivity. We need to be cautious in interpreting the results that depend on the existence and specification of the aggregate production function...That the use of the aggregate production function gives reasonably good estimates of factor productivity is due mainly to the narrow range of movement of aggregate data, rather than the solid foundation of the function. In fact, the aggregate production function does not have a conceptual reality of its own" (Nadiri 1970, pp.1145-46). 


\section{Table 3: Definition of Variables}

\begin{tabular}{|c|c|c|}
\hline Variables & Product Level & Aggregate Level \\
\hline Output & $\begin{array}{l}Q^{n}=\text { output in monetary values }(\$) \\
Q^{q}=\text { output in physical units (number of widgets) } \\
Q^{n}=p Q^{q} \\
p=\text { price per unit of output }(\$ / \text { widget) }\end{array}$ & $\begin{array}{l}Q^{n}=\text { output in monetary values }(\$) \\
Q=\text { output in real terms ( } \$ \text { of a base year) } \\
Q^{n}=P Q \\
P=\text { output deflator (index) }\end{array}$ \\
\hline Output identities & $\begin{array}{l}Q^{n} \equiv W^{n}+O S^{n} \equiv w^{n} L+r^{\$} K^{k}(\$) \\
Q^{n} \equiv W^{n}+C^{n}+Z^{n} \equiv w^{n} L+\rho^{\S} K^{k}+Z^{n}(\$), \\
\text { where } C^{n} \text { denotes total costs and } Z^{n} \text { monopoly profits } \\
Q^{q} \equiv W^{q}+O S^{q} \equiv w^{q} L+r^{q} K^{k} \text { (physical units) } \\
Q^{q} \equiv W^{q}+C^{q}+Z^{q} \equiv w^{q} L+\rho^{q} K^{k}+Z^{q} \\
\text { (physical units) }\end{array}$ & $\begin{array}{l}Q^{n} \equiv W^{n}+O S^{n} \equiv w^{n} L+r^{n} K(\$) \\
Q^{n} \equiv W^{n}+C^{n}+Z^{n} \equiv w^{n} L+\rho^{n} K+Z^{n}(\$), \\
\text { where } C^{n} \text { denotes total costs and } Z^{n} \text { monopoly profits } \\
Q \equiv W+O S \equiv w L+r K \text { (\$ of a base year) } \\
Q \equiv W+C+Z \equiv w L+\rho K+Z \\
\text { (\$ of a baseyear) }\end{array}$ \\
\hline Wage bill & $\begin{array}{l}W^{n}=\text { total wage bill }(\$) \\
W^{q}=\text { total wage cost in physical units (number of widgets) } \\
W^{n}=w^{n} L, w^{n}=\$ / \text { worker } \\
W^{q}=w^{q} L, w^{q}=w^{n} / p=\text { widgets } / \text { worker } \\
L=\text { number of workers }\end{array}$ & $\begin{array}{l}W^{n}=\text { total wage cost }(\$) \\
W=\text { total wage cost in real terms ( } \$ \text { of a base year) } \\
W^{n}=w^{n} L, w^{n}=\$ / \text { worker } \\
W=w L, w=\$ \text { (of a base year)/worker } \\
L=\text { number of workers }\end{array}$ \\
\hline Operating surplus & $\begin{array}{l}O S^{n}=\text { total profits }(\$) \\
O S^{q}=\text { total profits in physical units (e.g, number of } \\
\text { widgets) } \\
O S^{n}=r^{\S} K^{k}, r^{\S}=\text { ex post profit rate, derived from } \\
\text { variables in nominal terms ( } \$ \text { of profit per unit of physical } \\
\text { capital) } \\
O S^{q}=r^{q} K^{k}, r^{q}=\text { ex post profit rate, derived from } \\
\text { variables in physical units (profit in units of physical output } \\
\text { per unit of physical capital) } \\
K^{k}=\text { stock of capital (number of units of physical capital) }\end{array}$ & $\begin{array}{l}O S^{n}=\text { total profits }(\$) \\
O S=\text { total profits }(\$ \text { of a base year) } \\
O S^{n}=r^{n} K, r^{n}=\text { ex post profit rate, derived from } \\
\text { variables in nominal terms }(\%) \\
O S=r K, r=\text { ex post profit rate, derived from variables } \\
\text { in real terms }(\%) \\
K=\text { stock of capital ( } \$ \text { of a base year) }\end{array}$ \\
\hline $\begin{array}{l}\text { Total costs } \\
\text { (Identities) }\end{array}$ & $\begin{array}{l}C^{n} \equiv w^{n} L+\rho^{s} K^{k}(\$) \\
C^{q} \equiv w^{q} L+\rho^{q} K^{k} \text { (total cost in physical units, } \\
\text { number of widgets) } \\
C^{n}=p C^{q} \\
\text { cost of capital } \$=\rho^{\$} K^{k}(\$) \\
\text { cost of capital } q=\rho^{q} K^{k} \text { (number of widgets) } \\
K^{k}=\text { Number of machines (e.g., computers) } \\
\rho^{\$}=\text { rental price of capital }(\$ / \text { machine), theoretically } \\
\text { calculated as }\left(i+\delta-\hat{p}_{K}\right) p_{K} \\
\rho^{q}=\left(\rho^{\$} / p\right)=\text { rental price of capital in physical units } \\
\text { (widgets/machine) } \\
p_{K}=\text { price of the capital equipment }(\$ / \text { machine) }\end{array}$ & $\begin{array}{l}C^{n} \equiv w^{n} L+\rho^{n} K(\$) \\
\bar{Q} \equiv C \equiv w L+\rho K \text { (total cost in } \$ \text { of a base year) } \\
C^{n}=P C \\
\text { cost of capital: both } \rho^{n} K \text { and } \rho K \text { are in } \$ \\
\rho^{n}=\text { rental rate of capital (\%), calculated as } \\
\left(i+\delta-\hat{P}_{K}\right) P_{K} \\
\rho=\left(\rho^{n} / P\right)=\text { rental rate of capital in real terms (\%) } \\
P_{K}=\text { price deflator of capital (index) }\end{array}$ \\
\hline Factor shares & $\begin{array}{l}\text { All\% based on physical units in numerator and denominator } \\
\text { Revenue: } a^{q}=\left(w^{q} L / Q^{q}\right), 1-a^{q}=\left(r^{q} K^{k} / Q^{q}\right) \\
\text { Revenue: } \theta_{L}^{q}=\left(w^{q} L / Q^{q}\right), \theta_{K}^{q}=\left(\rho^{q} K^{K} / Q^{q}\right) \text {, } \\
\theta_{Z}^{q}=\left(Z^{q} / Q^{q}\right) \\
\text { Cost: } \vartheta_{L}^{q}=\left(w^{q} L / C^{q}\right), \vartheta_{K}^{q}=\left(\rho^{q} K^{q} / C^{q}\right)\end{array}$ & $\begin{array}{l}\text { All\% based on monetary values in numerator and } \\
\text { denominator } \\
\text { Revenue: } a=(w L / Q), 1-a=(r K / Q) \\
\text { Revenue: } \theta_{L}=(w L / Q), \theta_{K}=(\rho K / Q), \\
\theta_{Z}=(Z / Q) \\
\text { Cost: } \vartheta_{L}=(w L / C), \vartheta_{K}=(\rho K / C)\end{array}$ \\
\hline
\end{tabular}


Example 1: We start with Hsieh $(1999,2002)$ and his proposal to derive an estimate of TFP growth solely by using the income accounting identity. Hsieh argued that Young's $(1992,1995)$ calculations were problematic because the latter had used the primal measure of TFP growth, which required information on capital stocks (difficult to construct). Hsieh's point, in particular for Singapore, was that with a more or less constant share of capital in GDP and an increasing capital-output ratio, the implied rate of return should have fallen dramatically. The data Young had used overstated investment and hence the estimated stock of capital (and its growth rate) was too high. However, different measures of the marginal product of capital showed no decline. Hsieh then concluded that Singapore's national accounts overstated the amount of investment spending, the data used to construct the capital stock."

To solve this problem, Hsieh proposed to calculate the dual measure of TFP growth. The use of factor prices data required for the dual avoids the problems of the primal. As noted above, Hsieh (1999, 2002), however, did not derive the dual from the cost function. He instead derived it by expressing the national income accounting identity in value terms, equation (5), in growth rates as equation (6). Then he noted that the left-hand side looks like the primal derived from the production function, and the right-hand side like the dual derived from the cost function, i.e., $\hat{Q}_{t}-a_{t} \hat{L}_{t}-\left(1-a_{t}\right) \hat{K}_{t} \equiv a_{t} \hat{w}_{t}+\left(1-a_{t}\right) \hat{r}_{t}$. Hsieh, however, did not calculate $a_{t} \hat{w}_{t}+\left(1-a_{t}\right) \hat{r}_{t}$. Instead, he used equation (3), which requires an estimate of the rental rate of capital. Since the latter did not show a marked decline, Hsieh found higher TFP growth rates using the dual than using the primal (Table 2). ${ }^{2}$

What do we make, however, of Hsieh's $(1999,2002)$ dual in the light of the accounting identity? As we have already noted, Hsieh claimed that the dual could be derived directly from the national income accounts. This is not quite correct. To see why, we need to understand how the dual is derived from the cost function, as well as its interpretation at the microeconomic level. We will show that the aggregate level (Hsieh's identity and the variables he used), the units of the variables that make up TFP are different from those at the microeconomic (product) level. This makes the interpretation of the dual as a measure of overall productivity an impossible exercise. As we noted above, a careful reading of the paper suggests that underlying Hsieh's arguments and interpretation of the results are the microeconomic neoclassical production and cost functions in physical units (not in monetary values) and the imposed assumption of competitive factor markets, upon which the theory of TFP growth is based, and not just an accounting identity. In other words, theory and empirical work are not consistent with each other.

1 Young (1992) had made a similar point. Young's capital stock data implied that the rate of return had declined from $37 \%$ in the mid-1960s to $13 \%$ in the mid-1980s. This was very counterintuitive.

12 Young (1998b), commenting on an early version of Hsieh's work, argued that the latter's work was erroneous because it was full of methodological and computational errors. Young claimed, for example, that Hsieh's formula for the rental price of capital did not include the impact of changes in the tax code. The correct formula Hsieh should have used according to Young is: $\rho=\left(i+\delta-\hat{P}_{K}\right) P_{K}[(1-\tau D-E) /(1-\tau)]+t P_{B}$, where $D$ is the present discounted value of tax deductions for depreciation, $\tau$ is the corporate income tax rate, $E$ is the effective tax rate of investment tax credit, $t$ is the property tax rate, $P_{B}$ is the real property tax basis. Young also claimed that Hsieh's method generated negative rentals in levels. Once these alleged errors were corrected, Young showed that dual and primal produced the same result, a very low TFP growth rate for Singapore. Hsieh disagreed by pointing out that he did not have enough information on tax policies in these countries to calculate tax-adjusted rental prices (Hsieh 2002, footnote 14). He nevertheless used some aggregate data on Singapore to check this (Hsieh 2002, section IV) but concluded that the inclusion or not of taxes in the estimation of the rental price of capital does not explain the large discrepancy between primal and dual estimates of TFP growth. 
Definitions for variables in physical quantities and TFP. Let's start with the definitions at the microeconomic or product level. In neoclassical theory, the dual is derived from the cost function. In the Cobb-Douglas case, for example, $C_{t}^{n}=A\left(w_{t}^{n}\right)^{\alpha}\left(\rho_{t}^{\$}\right)^{\beta} Q^{q} e^{-\hat{\lambda} t}$ (assuming one type of labor and one type of capital good), where $C^{n}$ denotes total nominal costs cost, and $w^{n}$ and $\rho^{\$}$ denote the nominal wage rate (in dollars per worker), and the nominal rental price of a unit of homogeneous physical capital (in dollars per machine), respectively. The rental price of capital is the cost of using or renting capital for one period, the counterpart to the wage rate. Following Jorgenson and Hall (1967), it should be calculated as $\rho^{\$}=(i+\delta) p_{K}-\dot{p}_{K}=\left(i+\delta-\hat{p}_{K}\right) p_{K}$, where $i$ is the nominal cost of borrowing in the financial markets (some market rate, a percent), $p_{K}$ is the sale value of a unit of homogeneous capital (a dollar value), and $\hat{p}_{K}$ is the growth rate (a percent) of the capital price. We stress that the rental price of capital is a price, denoted with the superscript $\$$. Recall that here technical progress lowers the cost of obtaining a given output. Unit costs (a value term) are given by $c^{n}=C^{n} / Q^{q}$ and since $p Q^{q}=C^{n}$ (without monopoly profits), then $\hat{c}^{n}=\hat{p}$, that is: $\hat{c}^{n}=-\hat{\lambda}+\alpha \hat{w}_{t}^{n}+\beta \hat{\rho}_{t}^{\mathrm{S}}=\hat{p}$. This implies that the rate of technical progress in physical terms is given by the expression $\hat{\lambda}=\alpha \hat{w}_{t}^{q}+(1-\alpha) \hat{\rho}_{t}^{q}$ (assuming constant returns to scale), where $w^{q}=w^{n} / p$ and $\rho^{q}=\rho^{\$} / p$. Note that the factor prices are measured in units of physical output (widgets) per worker, and in units of physical output per unit of physical capital (e.g., per square meter of office, per computer). Both are clearly measures of labor and capital productivity, respectively.

We move now to the units in the accounting identity. Here we have identities parallel to (4) and to (5) (i.e., $Q_{t}^{n} \equiv W_{t}^{n}+O S_{t}^{n} \equiv w_{t}^{n} L_{t}+r_{t}^{\$} K_{t}^{k}$ and $Q_{t}^{q} \equiv W_{t}^{q}+O S_{t}^{q} \equiv w_{t}^{n} L_{t}+r_{t}^{q} K_{t}^{k}$, where $K^{k}$ is the stock of capital measured in physical units, e.g., square meters of office space, number of computers. Note that now the units of the corresponding ex post profit rates are dollars of profit per unit of physical capital $\left(r^{\$}\right)$, and profit in units of physical output (e.g., number of widgets) per unit of physical capital $\left(r^{q}\right)$. The identities consistent with the neoclassical microeconomic cost function would be:

$$
C_{t}^{n} \equiv p_{t} C_{t}^{q} \equiv w_{t}^{n} L_{t}+\rho_{t}^{\S} K_{t}^{k}
$$

and $C_{t}^{q} \equiv w_{t}^{q} L_{t}+\rho_{t}^{q} K_{t}^{k}$ (in physical units), where, once again, $\rho^{q}$ denotes the real rental price of a unit of homogeneous physical capital (in units of physical output per unit of physical capital), denoted by $K^{k}$. The real wage rate $w^{q}$ is measured in units of physical output per worker, and $C^{q}$ is also measured in physical units of output. Naturally, if there were several types of labor and capital, identity (7) would be $C_{t}^{n} \equiv p_{t} C_{t}^{q} \equiv \sum w_{t}^{n} L_{t}+\sum \rho_{t}^{\$} K_{t}^{k}$. We simplify it and assume one type of each. The possible difference between $Q^{n}$ and $C^{n}$ is due to the existence of economic profits. The difference between the growth rates of the two cost identities for $C_{t}^{n}$ and $C_{t}^{q}$ equals the growth rate of the price, i.e., $\hat{C}^{n}-\hat{C}^{q}=\hat{p}$, that is, $\hat{C}_{t}^{n}-\hat{C}_{t}^{q} \equiv \hat{p}_{t} \equiv a_{t}^{q}\left(\hat{w}_{t}^{n}-\hat{w}_{t}^{q}\right)+\left(1-a_{t}^{q}\right)\left(\rho_{t}^{\$}-\rho_{t}^{q}\right)$, where $a^{q}=w^{q} L / Q^{q}$ and $\left(1-a^{q}\right)=\rho^{q} K^{k} / Q^{q}$ denote the two factor shares in physical units, i.e., percentage of physical cost (output) from labor and from capital, respectively. ${ }^{13}$ It then follows that the rate of cost reduction equals:

$$
\hat{p}_{t}-\left[a_{t}^{q} \hat{w}_{t}^{n}+\left(1-a_{t}^{q}\right) \hat{\rho}_{t}^{\$}\right] \equiv-\left[a_{t}^{q} \hat{w}_{t}^{q}+\left(1-a_{t}^{q}\right) \hat{\rho}_{t}^{q}\right] \equiv \widehat{T F P}_{t}^{D q}
$$

13 The expression we have written for the difference between the growth rates of the two cost identities assumes that the shares of labor and capital in monetary values (percentage of total cost in monetary values, i.e., $a=w^{n} L / C^{n}$ ) and in physical quantities (percentage of total cost in physical terms, i.e., $a^{q}$ ), from the respective identities, are the same. 
which looks like expression (3) above but it is not (see below). The reason why expression (8) correctly measures the rate of cost reduction is that the real wage rate is expressed in units of output per worker and the rental price of capital is expressed in units of physical output per unit of physical capital, both measures of productivity. The assumption is that the standard formula of the rental price of capital provides a correct estimate of the cost of renting a unit of capital. Likewise, the capital stock is measured in physical units too (e.g., square meters of office, number of identical computers). Therefore, since the two factor prices are measured correctly in physical units, we know the meaning of the rate of cost reduction. In the standard TFP language, the latter would be (in levels and assuming constant factor shares to simplify): $\ln T F P_{t}^{q} \equiv \ln C^{q}-a^{q} \ln L-\left(1-a^{q}\right) \ln K^{k} \equiv a^{q} \ln w^{q}+\left(1-a^{q}\right) \ln \rho^{q} \equiv T F P_{t}^{D q}$, with units (number of widgets - number of workers - units of physical capital) in the primal, and (widgets per worker + widgets per unit of physical capital) in the dual. Units match and the expression makes sense as a measure of overall productivity, and consequently so does in growth rates $\widehat{T F P}_{t}^{q}$ and $\widehat{T F P}_{t}^{D q}$. We shall return to the identity in physical quantities in section $\mathrm{V}$.

Aggregate level definitions and aggregate TFP. What is the difference when the data used are aggregates, as is the case of the literature discussed? Let's recall identity (5) (in real terms), $Q_{t} \equiv w_{t} L_{t}+r_{t} K_{t}$. Here $Q$ and $K$ are aggregate value measures in, for example, dollars (of a base year) and $w$ is the wage rate in dollars (of a base year) per worker. As shown above, the economy's average ex post profit rate $r$ is the one that makes $Q \equiv w L+r K$ internally consistent with the NIPA.

The accounting identity that is consistent with Hsieh's calculations is, conceptually, different from equation (5). The trick is to mimic the identity with physical quantities while using aggregates. This, however, runs into problems. First, the capital stock $K$ is a monetary value (dollars). Second, Hsieh's identity does not use the ex post profit rate, but instead estimates a rental rate of capital. This is different from the rental price of capital with physical quantities discussed above. The reason is that since there is no information on the individual capital prices $p_{K}$ (dollars) of the capital goods, researchers use a price deflator $\left(P_{K}\right)$ in the same formula. This is not an innocuous variation. It implies that the real rental rate of capital $\rho=\left(i+\delta-\hat{P}_{K}\right)\left(P_{K} / P\right)$ that he calculates is not a physical quantity but a percent times the ratio of two deflators, although since the capital stock is now a value, $\rho K$ remains a dollar value, the same as at the product level (i.e., the identity is consistent). Given that both the rental rate of capital $\rho$ and the stock of capital $K$ are calculated independently, the product $\rho K$ need not be equal to the operating surplus (unlike $r K$ in equation [5]). Therefore, the accounting identity effectively used by Hsieh may not be consistent with the NIPA because there is no guarantee that $Q_{t}$ equals $w_{t} L_{t}+\rho_{t} K_{t}$. This means that under these circumstances, and to be consistent, Hsieh's income accounting identity should be written as:

$$
\bar{Q}_{t} \equiv w_{t} L_{t}+\rho_{t} K_{t}
$$

where now $\bar{Q}_{t}$ is constructed using the four series on the right-hand side. This could be defined as the GDP consistent with competitive markets, given that wage and rental rate of capital are thought to be the competitively determined factor prices. It can also be referred to as the cost identity $(\bar{Q}=C)$. Naturally, whether the estimate of $\bar{Q}$ is correct or not depends on whether the series used to calculate it, in particular $\rho$ and $K$, are correct or not. This identity gives us the labor and capital cost shares 
$\vartheta_{L}=(w L / C)$ and $\vartheta_{K}=(\rho K / C)$, respectively, with $\vartheta_{L}+\vartheta_{K}=1$. One could perform a growth accounting exercise and calculate TFP growth as:

$$
\widehat{T F P}_{t}^{2} \equiv \hat{\bar{Q}}_{t}-\vartheta_{L t} \hat{L}_{t}-\vartheta_{K t} \hat{K}_{t} \equiv \vartheta_{L t} \hat{w}_{t}+\vartheta_{K t} \hat{\rho}_{t} \equiv \widehat{T F P}_{t}^{D 2}
$$

Note that, in general, $\bar{Q}(C$ ) will differ from $Q$ (actual GDP) as the latter appears in the NIPA (Hsieh 2002, p.505). The difference is attributed to the existence of pure profits. Given this, the actual GDP identity could also be written as:

$$
Q_{t} \equiv C_{t}+Z_{t} \equiv w_{t} L_{t}+\rho_{t} K_{t}+Z_{t}
$$

where $\mathrm{Z}$ denotes pure profits and, where for consistency, $O S_{t} \equiv r_{t} K_{t} \equiv \rho_{t} K_{t}+Z_{t}$. In this case, the GDP shares are $\theta_{L}=a_{t}=(w L / Q), \theta_{K}=(\rho K / Q)$ and $\theta_{Z}=(Z / Q)$, with $\theta_{L}+\theta_{K}+\theta_{Z}=1$. One can also express this last identity in growth rates to undertake a growth accounting exercise as:

$$
\widehat{T F P}_{t}^{3} \equiv \hat{Q}_{t}-\theta_{L t} \hat{L}_{t}+\theta_{K t} \hat{K}_{t} \equiv \theta_{L t} \hat{w}_{t}+\theta_{K t} \hat{\rho}_{t}+\theta_{Z t} \hat{Z}_{t} \equiv \widehat{T F P}_{t}^{D 3}
$$

Now the dual of TFP growth splits the contribution of the growth rate of the operating surplus into that of the cost of capital and that of pure profits. One could also argue that monopoly profits are extracted from labor and that the latter's true share should be $\theta^{*}=[(w L+Z) / Q]$. This does not alter the argument. The slight differences between identities (12), (10), and (6) with aggregate data are obvious (different shares, $a, \theta, \vartheta$ ). It should also be obvious that they would yield different results; and that if one calculates the primal using one of them and the dual using another one, results will differ. What is of utmost importance is that, all these three equations are conceptually very different from (8).

The last point about splitting the operating surplus into the cost of capital and pure profits was the basis for the growth accounting approach (i.e., no testing involved) that Fernald and Neiman (2011) developed. Through a series of assumptions, they decomposed overall TFP growth into the contribution of "true" aggregate technology and two terms that pick up differences in market power (profits) across different sectors of the economy (related to differences between GDP and cost shares) and sectoral reallocation of capital across uses. ${ }^{14}$ Their point is that to measure properly aggregate technology growth, one needs to use sectoral data, as aggregate TFP growth depends not only on aggregate technology but

14 This literature relates economic profits to firms' markups following the seminal work of Robert Hall (1988, 1990). The problem with Hall's method to estimate markups is that it is also invalidated by the accounting identity. Hall's model led to the following regression equation: $\left(\hat{Q}_{t}-\hat{K}_{t}\right) \equiv a+\mu\left(a_{t} \hat{n}_{t}\right)+u_{t}$, where $\hat{n}_{t}=\hat{L}_{t}-\hat{K}_{t}$ and $\mu$ is the markup. For estimation purposes, he ran the inverse of this regression, that is, $\left(a_{t} \hat{n}_{t}\right)=c+d\left(\hat{Q}_{t}-\hat{K}_{t}\right)+u_{t}$, where now the estimate of the markup would be $\tilde{\mu}=(1 / \tilde{d})$. What is the problem? Note that the identity equation (5) in real terms can be written as $\left(\hat{Q}_{t}-\hat{K}_{t}\right) \equiv \hat{\varphi}_{t}+\left(a_{t} \hat{n}_{t}\right)$, with $\hat{\varphi}_{t} \equiv a_{t} \hat{w}_{t}+\left(1-a_{t}\right) \hat{r}_{t}$. Clearly, if one estimates $\left(\hat{Q}_{t}-\hat{K}_{t}\right) \equiv \tau \hat{\varphi}_{t}+\mu\left(a_{t} \hat{n}_{t}\right)+u_{t}$, the result will be $\tilde{\tau}=\tilde{\mu}=1$ with a perfect fit. If, however, one estimates $\left(\hat{Q}_{t}-\hat{K}_{t}\right)=\hat{\varphi}+\mu\left(a_{t} \hat{n}_{t}\right)+u_{t}$, i.e., by forcing $\hat{\varphi}_{t}$ to be a constant, then it is obvious that the estimate of $\mu$ may differ from unity, as it happened to Hall (who found putative large markups) and to those who followed his procedure, e.g., Kee (2002) for Singapore. 
also on an adjustment for whether input use is growing faster in a high-profit sector or in a low-profit sector. ${ }^{15}$

When Fernald and Neiman (2011) revisited Singapore's puzzle with their methodology, they found that proper technology growth was slightly negative, despite the sizeable distortions introduced by large government subsidies through differential tax treatments and loan rates. Overall, their results were not very different from those of Young $(1992,1994,1995)$, in that pure technical progress was nil (“...even Young's primal results were insufficiently pessimistic", p.30). They also concluded that capital sectoral reallocation in Singapore had a minor impact on Singapore's growth despite considerable differences in sectors' returns and growth rates of capital. Overall, they concluded that "Singapore...achieved less with more!" (Fernald and Neiman 2011, p.57). ${ }^{16}$

One can certainly use the cost shares $\vartheta_{i}$, write overall GDP as the summation of the GDPs of different sectors of the economy, and use the relationship between GDP and cost shares, i.e., $\theta_{L}=(\psi / \mu) \vartheta_{L}$ for the labor share, where $\psi$ is the degree of returns to scale (the ratio of average to marginal cost) and the markup $\mu$ (the ratio of price to marginal cost) (Hall 1988, 1990). All these can be plugged into the identity (12) and rearrange terms suitably. Certainly, some terms could be interpreted as the effect of sectoral reallocation (in this setting, they will depend on the markup and profits), and there would be a residual term. However, it is important not to forget that all this will remain within the realm of the accounting identity. Naturally, assumptions made in the process (e.g., that a certain variable is constant when it is not) will affect the result but the effect will be hidden in growth accounting as whatever mistake is made will be reflected in a higher/lower residual term. Only the econometric estimation of an equation without any assumptions would show the underlying identity.

Given all the above, are the expressions for TFP growth in equations (6), (10), or (12) a measure of aggregate technical progress parallel to that in expression (8), derived from physical quantities? Our view is that they are not. What researchers do to calculate the cost identity $C_{t} \equiv w_{t} L_{t}+\rho_{t} K_{t}$ is to construct two variables $\rho$ and $K$ that try to mimic the rental price of capital $\left(\rho^{q}\right)$ and the stock of capital with physical units $\left(K^{k}\right)$. As discussed above, however, the two aggregate variables are very different in nature from their microcounterparts, especially taking into account that there is no agreement in the literature about the precise interest rate $(i)$ that should be used in the formula for the rental rate, and the assumptions made to calculate capital stocks. Therefore, although it is true that the product $\rho_{t} K_{t}$ yields a dollar figure, it is impossible to ascertain whether it correctly represents true total

15 The Fernald and Neiman decomposition is reminiscent of the decomposition obtained from the sectors' value added ( $Q \equiv Q^{A}+Q^{I}+Q^{S}$, where the superscripts denote agriculture, industry, and services, respectively), written in growth rates. In fact, there is a well-known decomposition in the literature that follows directly from this identity. This is the old decomposition of economywide labor productivity growth into the sum of intrasectoral labor productivity growth rates plus the effect of labor reallocation across sectors, i.e., $\Delta y \equiv \Sigma \theta_{i} \Delta y_{i}+\Sigma y_{i} \Delta \theta_{i}$, where $y$ is aggregate labor productivity, $y_{i}$ is sector $i$ labor productivity, $\theta_{i}$ is the share of employment in sector $i$, and the operator $\Delta$ denotes the change in productivity or in employment shares of each sector (e.g., see Asian Development Bank 2013). Naturally, it should be clearly recognized that this expression is based on a definition, not on a model.

16 Fernald and Neiman (2011) do acknowledge the accounting identity but they do not realize the isomorphism with the production function as a result of using value data. Moreover, they make statements such as "If the data satisfy the accounting identity (i.e., they are internally consistent)...." (Fernald and Neiman 2011, p.36; italics added). Is it possible that the data does not satisfy the cost and income identities? If this is the case, then we know that at least one of the series is incorrect. All one needs to do is to reconstruct the identity with the correct data....until it holds. 
payments to capital, which affects the reliability of the cost shares $\vartheta_{i} \cdot{ }^{17}$ This means that it is likely that $\rho_{t} K_{t}$ differs from $\Sigma\left(\rho_{t}^{\S} K_{t}^{k}\right)$ with physical quantities (summation across the many types of capital goods). Researchers then subtract this amount from the surplus in the NIPA to obtain a measure of pure profits (i.e., $O S_{t}-\rho_{t} K_{t} \equiv Z_{t}$ ). Naturally, there is no way to know either whether $Z_{t}$ actually and correctly measures monopolistic profits. Moreover, while with physical quantities both the real wage rate and the real rental price of capital are measured in physical quantities and are measures of labor and capital productivity, this is not the case at the aggregate level as the real wage rate is measured in dollars (of a base year) per worker, and the real rental rate of capital is the product of a percent $\left(i+\delta-\hat{P}_{K}\right)$ times the ratio of two deflators and $\left(P_{K} / P\right)$, i.e., unitless [while $\left(p_{K} / p\right)$ is number of widgets per machine]. This problem naturally remains despite disaggregating the total capital stock into subcategories, as long as these as not true physical quantities. ${ }^{18}$ In the standard TFP language, the latter would be (in levels and assuming constant factor shares to simplify): $\ln T F P_{t} \equiv \ln Q-a \ln L-(1-a) \ln K \equiv a \ln w+(1-a) \ln \rho \equiv T F P_{t}^{D}$, with units (dollars of a base year - number of workers - dollars of a base year) in the primal, and (dollars of a base year per worker + a percentage) in the dual. Units match but the expression does not make sense as a measure of productivity. This leads to the conclusion that $\widehat{T F P}_{t}^{i}$ or $\widehat{T F P}_{t}^{D i}$ are not measures of the aggregate rate of cost reduction or technical progress, should this exist (recall the arguments in section III about the aggregation problem). ${ }^{19}$ This problem gets masqueraded because the putative measure of technical progress is expressed as a growth rate.

Summing up: we have shown that the three equations considered at the aggregate level, expressions (5)-(6), (9)-(10), and (11)-(12), are identities that all data sets must satisfy. Surely identities are correct but they do not tell us more than what is obviously embedded in them. Moreover, at the aggregate level, the dual derived from the aggregate cost identity is not the same as that derived from physical quantities. This is because the corresponding prices are very different conceptually. This makes the interpretation of the aggregate one as a measure of productivity more than questionable.

Example 2: It should be obvious by now that Young's $(1992,1995)$ estimations of the primal of TFP growth can be recast in terms of the accounting identity equation (6) because he used value data. We have argued that, for using constant-price value data, the series in equations (2) and (6), are the same. As a consequence, it is impossible to interpret estimates of the primal $\widehat{\operatorname{TFP}}_{t}^{1} \equiv \hat{Q}_{t}-a_{t} \hat{L}_{t}-\left(1-a_{t}\right) \hat{K}_{t}$ as unequivocally implying anything about technical progress. Given equation (6), we can explain what Young's results using the primal mean from the dual's point of view. If the growth accounting primal was zero in Young's $(1992,1995)$ calculations [i.e., $\widehat{T F P}_{t}^{1} \equiv \hat{Q}_{t}-a_{t} \hat{L}_{t}-\left(1-a_{t}\right) \hat{K}_{t} \equiv 0$ ], the identity implies that the dual must be $\widehat{T F P}_{t}^{D 1} \equiv a_{t} \hat{w}_{t}+\left(1-a_{t}\right) \hat{r}_{t} \equiv 0$. With a capital share more or less constant and taking on a value of approximately 0.5 , this expression implies that $\hat{w}_{t} \cong-\hat{r}_{t}$ for Singapore. In other words, the wage rate grew at a rate that was approximately matched by the decline in the growth rate of the ex post profit

17 Note, however, that the surplus in the NIPA calculated as $O S^{n} \equiv Q^{n}-W^{n}$ (equation [4]) is correct to the extent that national accounts statisticians impute properly aspects such as self-employment income (as wages and not as profits). This is the case of advanced economies but no so of many developing countries.

18 We believe that this confusion can be traced back to Jorgensen and Griliches (1967), who regarded and treated the aggregate rental rate of capital as if it were that with physical quantities, a true price (dollars per unit of capital stock), and the capital stock as if it were a physical measure. That is, their theoretical work and derivations used physical quantities but their empirical work used the aggregates.

19 This means that it is possible that $\widehat{T F P}_{t}^{i}$ take on any value, including negative or zero (recall how $\rho$ is calculated, hence $\hat{\rho}$ is the growth rate of an interest rate), while $\widehat{T F P}_{t}^{q}$ is positive. 
rate. This may be an interesting finding, but recall that it has been derived directly from an accounting identity. Nevertheless, this is the point Hsieh disagreed with (i.e., the fast decline in the profit rate), as he argued that it was caused by the very high and possibly incorrect estimates of the capital stock.

We can further elaborate on why one does not learn anything from this literature by reviewing Young's (1994) growth accounting exercise, performed not by using equation (2), but instead by estimating a growth regression. Young estimated a cross-country production function using data for 118 countries for 1970-1985. This was the growth accounting regression $\hat{Q}_{t}=\hat{\varphi}+\gamma_{1} \hat{L}_{t}+\gamma_{2} \hat{K}_{t}+u_{t}$, or $\left(\hat{Q}_{t}-\hat{L}\right)_{t}=\hat{\varphi}+\gamma_{2}\left(\hat{K}_{t}-\hat{L}_{t}\right)+u_{t}$, under the assumption that $\gamma_{1}+\gamma_{2}=1$. As argued above, this was thought to be a model in the sense that it can be tested and potentially refuted. Each country residual $\hat{u}_{i}$ measures the growth of country i's TFP less the world average. That is, the per country TFP growth rate equals $\tilde{\varphi}+\tilde{u}_{i}$, where the symbol $\sim$ denotes a statistical estimate. Young obtained the following result:

$$
\left(\hat{Q}_{i}-\hat{L}_{i}\right)=-0.21+0.45\left(\hat{K}_{i}-\hat{L}_{i}\right)+u_{i}
$$

He noted that the residuals for the East Asian economies $\left(\tilde{\phi}+\tilde{u}_{i}\right)$ were very close in value to his much more detailed analysis using the growth accounting methodology.

The question is: what does this regression tell us? We know from the accounting identity equation (6) that $\hat{Q}_{i} \equiv a_{i} \hat{w}_{i}+\left(1-a_{i}\right) \hat{r}_{i}+a_{i} \hat{L}_{i}+\left(1-a_{i}\right) \hat{K}_{i}$, or $\left(\hat{Q}_{i}-\hat{L}_{i}\right) \equiv a_{i} \hat{w}_{i}+\left(1-a_{i}\right) \hat{r}_{i}+\left(1-a_{i}\right)\left(\hat{K}_{i}-\hat{L}_{i}\right)$, where the subscript $i$ denotes the ith country. It will be recalled that, as argued earlier, this is not a model that the data can refute. This means that if one estimated econometrically equation (6) as $\left(\hat{Q}_{i}-\hat{L}_{i}\right) \equiv \mu_{1} \hat{\varphi}_{i}+\mu_{2}\left(\widehat{K / L}_{i}+u_{i}\right.$, where the two right-hand-side variables are constructed as $\hat{\varphi}_{i}=a_{i} \hat{w}_{i}+\left(1-a_{i}\right) \hat{r}_{i}$ and $(\widehat{K / L})_{i}=\left(1-a_{i}\right)\left(\hat{K}_{i}-\hat{L}_{i}\right)$, it should be obvious that the result must be $\tilde{\mu}_{1}=\tilde{\mu}_{2}=1$ and $R^{2}=1$ as there is no error term ( $u_{i}=0$ for all observations). Consequently, if one estimates:

$$
\left(\hat{Q}_{i}-\hat{L}_{i}\right)=c+\omega\left(\hat{K}_{i}-\hat{L}_{i}\right)+u_{i}
$$

as Young did, it should be apparent that the estimate of $\omega$ will pick up the average value of the share of capital in the sample $\left(1-\bar{a}_{i}\right)$. The sum of the error plus the constant will, by definition, provide an estimate of $\hat{\varphi}_{i}$, the weighted average of the wage and profit rates. Of course, the estimates may be subject to some bias if $\hat{\varphi}_{i}$ is not orthogonal to $\left(\hat{K}_{i}-\hat{L}_{i}\right)$. Note that equation (14) contains the error term $u_{i}$. This is not zero as in the accounting identity (6) because equation (14) proxies $a_{i} \hat{w}_{i}+\left(1-a_{i}\right) \hat{r}_{i}$ by the constant term $c$, and $\left(1-a_{i}\right)$ by the coefficient $\omega$ (also constant). To the extent that these two variables are not constant, left- and right-hand sides of equation (14) will not be identical. It should be clear, nevertheless, that the nature of this error term is different from that in a true economic model, i.e., random error that results from other factors not considered. Young's estimates of TFPG of the East Asian economies from the regression exercise must be virtually identical to those from the accounting identity. The latter shows that it cannot be otherwise.

Example 3: Wong and Gan (1994) tested the equality of primal and dual with data for Singapore. They estimated the regression $\widehat{T F P}_{t}=c+\tau \widehat{T F P}_{t}^{D}+u_{t} \quad$ where $\widehat{T F P}_{t} \equiv \hat{Q}_{t}-a_{t} \hat{L}_{t}-\left(1-a_{t}\right) \hat{K}_{t}$ and $\widehat{T F P}_{t}^{D} \equiv \vartheta_{L t} \hat{w}_{t}+\vartheta_{K t} \hat{\rho}_{t}$, for 27 manufacturing industries, and tested the null hypothesis $\tau=1$ (Wong and 
Gan 1994, Table 5). ${ }^{20}$ They seemingly derived the primal and dual measures of TFP growth "independently," from the production and cost functions, respectively. As we showed above, however, this is not true since both use values and hence are related through the accounting identity. To calculate the dual $\widehat{T F P}_{t}^{D}$, they estimated and used the rental rate of capital $\rho$ (though see below).

In a second exercise, they added an additional explanatory variable to the same regression, a measure of industry demand $(\hat{X})$, to test the Keynesian theory that movements in demand drive TFP growth: $\widehat{T F P}_{t}=c+\tau \widehat{T F P}_{t}^{D}+\phi \hat{X}_{t}+u_{t}$, where $\hat{X}_{t}$ is the growth of industry (Wong and Gan 1994, Table 6).

What did Wong and Gan find? In their first set of regressions, except in one case, they found that the estimates of the coefficients $\tau$ were virtually 1 and quite tightly estimated (with $\mathrm{t}$-values above 100 and up to 454), and the regressions had almost perfect fits ( $R^{2}>0.99$ in most cases). The authors concluded that their findings suggested that "the movements in TFP growth reflect true changes in productivity." In their second set, the extended regressions, their results were $\tau=1$ and $\phi=0$ across most industries. Wong and Gan interpreted the finding that $\phi=0$ as a refutation of the Keynesian theory.

In view of our discussion, however, the results discussed above should not come as a surprise, but should be very much expected. Regressing $\widehat{T F P}_{t}$ on $\widehat{T F P}_{t}^{D}$ is meaningless because they are the same variable. The interesting question is: why did Wong and Gan systematically and across most of the 27 industries estimated slopes of the regressions of TFP growth primal on TFP growth dual equal to unity (with, as we have noted, extremely high t-values and an almost perfect fit), despite that they claimed that they had estimated and used the rental rate of capital $\rho$ (theoretically different from the ex post profit rate $r$ ) and not through the identity (5)? The answer, in terms of our arguments, is straightforward: $\widehat{T F P}_{t}$ and $\widehat{T F P}_{t}^{D}$ had to be the same variable. Why was this the case? There is only one possible reason: the rental rate of capital that they estimated had to be virtually identical to the profit rate consistent with the accounting identity (5). Indeed this was the case if one looks at how they proceeded to calculate the rental price of capital (see Appendix of their paper, in particular their equation [13]). They considered four types of capital assets (nonresidential buildings, machinery and equipment, office equipment, and transport equipment), each with its own rental rate $\rho$ (but with the same rate of return $i$ for the four assets), in each of the 27 industries. To compute each of the 27 industries' rate of return (unknown in their scheme), they equated the sum of the values of capital services over the four assets $(i=1 \ldots 4)$ to total payments to capital of the industry $\left(j=1 \ldots 27\right.$ ), i.e., $\Sigma \rho_{i} K_{i} \equiv O S$ for a given industry, where $O S$ denotes "total payments to capital derived as a residual of output after all other inputs have been paid." In other words, Wong and Gan effectively used the accounting identity (4) and, therefore, it is not surprising that their rental rate of capital was equal to the ex post profit rate, with the consequence that output and cost shares were about the same. ${ }^{21}$

20 Their calculations of $\widehat{T F P}_{t}$ and $\widehat{T F P}_{t}^{D}$ involved two additional terms each, corresponding to energy and materials, because their measure of industry output is gross output.

${ }_{21}$ One final point is that Wong and Gan (1994, Table 3) found higher TFP growth rates than Young (1992, Table VI) for manufacturing. This is interesting because as we argue in the text, the rental price of capital that they calculated should be the same as the profit rate. The reason for their higher TFP growth rates, we think, is that they worked with gross output (i.e., including energy and materials) rather than with value added. This means that their equation for the dual of TFP growth (equation [10] in their paper) contains four terms, the growth rates of the wage and profit rates, and also the growth rates of the price of energy, and the growth rate of the price of materials. These four terms add up to a higher TFP growth rate than with only the first two terms. 
Finally, their results $\tau=1$ and $\phi=0$ with the extended regression are also known without the need to run the regression: the regressor $\hat{X}_{t}$ does not add anything to their accounting identity regression, hence its coefficient must be zero.

Example 4: Kim and Lau's (1994) main methodological contribution was the estimation of a translog metaproduction function where they used panel data for nine economies, the four East Asian NIEs and the G5. Instead of using the production function in a growth accounting exercise like Young $(1992,1995)$, the econometric estimation of the supposed production function allowed them to test the key assumptions of growth accounting, namely, linear homogeneity of the production function and perfect competition. These are assumptions that most authors working in the field have not even discussed, but rather simply imposed them. Kim and Lau's work rejected both assumptions, although this important result seems to have passed unnoticed by the profession. They also concluded that technical progress was capital augmenting and that exogenous TFP growth in Asia's NIEs had been zero.

In the light of the accounting identity, however, we can also show that Kim and Lau's exercise was an approximation to equation (6). This example will also allow us to show how the isomorphism between the accounting identity and the value production function equally applies to the case when factor shares are not constant and when technical progress is not assumed to be Hicks neutral.

Kim and Lau hypothesized a transcendental logarithmic production function $Q=F\left(A_{L} L, A_{K} K\right)$, where $A_{L t}$ and $A_{K t}$ are the levels of factor-augmenting technology (allowed to differ across countries), with inputs expressed in efficiency units:

$$
\ln Q=\ln A_{0}+\alpha \ln A_{L t} L_{t}+\beta \ln A_{K t} K_{t}+\gamma\left(\ln A_{L t} L_{t} \ln A_{K t} K_{t}\right)+\delta\left(\ln A_{L t} L_{t}\right)^{2}+\phi\left(\ln A_{K t} K_{t}\right)^{2}+u_{t}
$$

Substituting $\ln A_{L t}=\ln A_{L 0}+\hat{\lambda}_{L} t$ and $\ln A_{K t}=\ln A_{K 0}+\hat{\lambda}_{K} t$ (where $A_{L 0}$ and $A_{K 0}$ are the initial levels and $\hat{\lambda}_{L}$ and $\hat{\lambda}_{K}$ are the rates of labor and capital-augmenting technical change) into the production function leads to an expression that can compressed into:

$$
\begin{aligned}
\ln Q=c+b_{1} \ln L_{t}+b_{2} \ln K_{t} & +b_{3}\left(\ln K_{t}\right)^{2}+b_{4}\left(\ln L_{t}\right)^{2}+b_{5}\left(\ln L_{t} \ln K_{t}\right)+b_{6}\left(t \ln K_{t}\right)+ \\
& +b_{7}\left(t \ln L_{t}\right)+b_{8} t+b_{9} t^{2}+u_{t}
\end{aligned}
$$

where $c$ and $b_{1} \ldots b_{8}$ are functions of the coefficients in the production function. Equation (16) was estimated by Kim and Lau in first differences together with the corresponding first-order condition for labor, i.e., a system of two equations. This follows from the argument that estimation of the production function alone is inappropriate as it treats labor and capital as exogenous variables. Consequently, as $A_{L 0}$ and $A_{K 0}$ differ across countries, the coefficients $c, b_{1}, b_{2}$, and $b_{8}$ are country-specific constants. The first-order condition for labor is obtained by differentiating the production function with respect to labor, that is,

$$
\partial \ln Q / \partial \ln L=\left(\alpha+\gamma \ln A_{K 0}+2 \delta \ln A_{L 0}\right)+\left(2 \delta \lambda_{L}+\gamma \lambda_{K}\right) t+2 \delta \ln L_{t}+\gamma \ln K_{t}+u_{t}
$$

If profit maximization and perfect competition hold, this will be equal to the share of labor in GDP, i.e., $\partial \ln Q / \partial \ln L=a$. Therefore, the test of the assumption of a competitive labor market is whether the output elasticities equal the factor shares. 
However, in the light of our earlier comments, this method is invalidated by the accounting identity. To see this, differentiate equation (16) with respect to time to express it in growth rates. This yields (disregarding the error term):

$$
\begin{gathered}
\hat{Q}_{t}=\alpha_{t}^{\prime} \lambda_{L}+\beta_{t}^{\prime} \lambda_{K}+\alpha_{t}^{\prime} \hat{L}_{t}+\beta_{t}^{\prime} \hat{K}_{t} \\
\text { with } \alpha_{t}^{\prime}=\left(\alpha+\gamma \ln A_{K 0}+2 \delta \ln A_{L 0}\right)+\left(2 \delta \lambda_{L}+\gamma \lambda_{K}\right) t+2 \delta \ln L_{t}+\gamma \ln K_{t} \\
\text { and } \beta_{t}^{\prime}=\left(\beta+\gamma \ln A_{L 0}+2 \phi \ln A_{K 0}\right)+\left(2 \phi \lambda_{K}+\gamma \lambda_{L}\right) t+2 \phi \ln K_{t}+\gamma \ln L_{t}
\end{gathered}
$$

where $\alpha_{t}^{\prime}$ and $\beta_{t}^{\prime}$ are the respective output elasticities. It thus follows from the above (the first-order condition and equations [19] and [20]) that if the labor market is perfectly competitive, the following must be true:

$$
\hat{Q}_{t}=a_{t} \hat{\lambda}_{L}+\left(1-a_{t}\right) \hat{\lambda}_{K}+a_{t} \hat{L}_{t}+\left(1-a_{t}\right) \hat{K}_{t}=\hat{\eta}_{t}+a_{t} \hat{L}_{t}+\left(1-a_{t}\right) \hat{K}_{t}
$$

Now compare equation (21) with the identity equation (6), i.e., $\hat{Q}_{t} \equiv a_{t} \hat{w}_{t}+\left(1-a_{t}\right) \hat{r}_{t}+a_{t} \hat{L}_{t}+\left(1-a_{t}\right) \hat{K}_{t} \equiv \hat{\lambda}_{t}+a_{t} \hat{L}_{t}+\left(1-a_{t}\right) \hat{K}_{t}$. Suppose that equation (18) is estimated unrestricted. It should be obvious that (18) will always hold by virtue of (6). Once again, we see that it is not possible to test, in the sense of potentially refuting, the hypothesis that the elasticity of output with respect to labor equals the share of labor, i.e., that the labor market is perfectly competitive. This also shows that the Kim and Lau procedure must indicate that there are constant returns to scale.

Given the above, how did Kim and Lau claim to have refuted the growth accounting underlying assumptions? Suppose factor shares do not follow closely the paths in equations (19) and (20), and recall that Kim and Lau pooled data for nine countries, then their translog production function will seem to imply that they reject the null hypothesis. However, as we explained earlier, this is simply a matter of finding the correct path. We will always return to the identity.

Example 5: Nelson and Pack's (1999) view was that the role of entrepreneurship, innovation, and learning, had been significant in these economies, and that Young had underestimated the rate of TFP growth in the NIEs because he had assumed Hicks-neutral technical progress when most likely this had been biased. This has important implications for the factor shares that affect the calculation of TFP growth in equation (2). Before we get to this point, let's see what the accounting identity critique implies for the estimation of TFP growth in a growth accounting exercise with biased technical progress.

Like Kim and Lau, Nelson and Pack assumed the production function $Q=F\left(A_{L} L, A_{K} K\right)$, where $A_{L}$ and $A_{K}$ represent factor-augmenting technical change. As shown in equation (21), in growth rates this becomes $\hat{Q}_{t}=a_{t} \hat{\lambda}_{L}+\left(1-a_{t}\right) \hat{\lambda}_{K}+a_{t} \hat{L}_{t}+\left(1-a_{t}\right) \hat{K}_{t}$, where $\hat{\lambda}_{L}$ and $\hat{\lambda}_{K}$ are the growth rates of factoraugmenting technical change (which might or might not be constant). This means that what is calculated as TFP growth is the weighted average of the rates of labor and capital-augmenting technical change, i.e., $\widehat{T F P}_{t}^{1} \equiv \hat{Q}_{t}-a_{t} \hat{L}_{t}-\left(1-a_{t}\right) \hat{K}_{t} \equiv a_{t} \hat{\lambda}_{L}+\left(1-a_{t}\right) \hat{\lambda}_{K} \equiv \widehat{T F P}_{t}^{4}$. Now recall that the accounting identity equation (6) is $\hat{Q}_{t} \equiv a_{t} \hat{w}_{t}+\left(1-a_{t}\right) \hat{r}_{t}+a_{t} \hat{L}_{t}+\left(1-a_{t}\right) \hat{K}_{t}$ and that it always holds. This implies that $\widehat{T F P}_{t}^{4} \equiv a_{t} \hat{\lambda}_{L}+\left(1-a_{t}\right) \hat{\lambda}_{K} \equiv a_{t} \hat{w}_{t}+\left(1-a_{t}\right) \hat{r}_{t} \equiv \widehat{T F P}_{t}^{D 4}$, that is, the weighted average of the rates of labor and capital-augmenting technical change must be identical to the weighted average of the growth rates of the wage and profit rate given by the identity. This is correct, although the precise interpretation of the 
results is open to question for the same reasons advanced earlier. Moreover, suppose one wanted to estimate econometrically the rates of labor and capital-augmenting technical change from the equation $\widehat{T F P}_{t}^{1}=c_{1} a_{t}+c_{2}\left(1-a_{t}\right)+u_{t}$. The result must be $c_{1}=\hat{w}_{t}=\hat{\lambda}_{L}$ and $c_{2}=\hat{r}_{t}=\hat{\lambda}_{K}$ by virtue of the accounting identity. Once again, this is a dead end for purposes of interpretation of the results if one believes that they are the outcome of a well-defined neoclassical production function with biased technical progress.

What was Nelson and Pack's (1999) point about the factor shares? This issue is unrelated to the accounting identity critique and requires some explanation. Their critique arose from the observation that capital shares in the NIPA had remained rather constant (in particular the capital share had not declined) in the East Asian economies during the miracle period despite a substantial increase in the capital-labor ratio. How could this be explained? In the neoclassical model, this can be seen to happen in two cases (Ferguson 1968): ${ }^{22}$ (i) if the underlying elasticity of substitution of the aggregate technology is unity, and with a Cobb-Douglas production function, technical change is Hicks (and Harrod) neutral; or (ii) if the elasticity of substitution differed from unity and technical progress was biased to the extent that, in spite of a rapidly growing capital-labor ratio, factor shares remained constant. Moreover, Nelson (1973) had already argued that the purpose of growth accounting is to separate the contribution of technological progress from that of factor accumulation. In doing this, the factor shares that multiply the growth rates of capital and labor in equation (2), i.e., $a_{t}$ and $\left(1-a_{t}\right)$, should be those that would have occurred if there had been no technical change. However, the factor shares actually used in these exercises are the observed ones, taken from the NIPA, which incorporate the effect of technical progress. If the latter is labor saving, purging this effect would reduce the capital share. A lower capital share, which multiplies the growth of capital - the fast-growing factor, would subtract less from output, thus leading to a higher TFP growth. Hence, the alleged puzzle is solved. In other words, if the observed stability of the factor shares was due to an elasticity of substitution that is less than unity and labor-saving technical change, the Nelson and Pack argument makes a substantial difference to the estimates of TFP growth. Nelson and Pack argued that it was difficult to assume that technical progress in East Asia had been Hicks neutral, implying that equal proportionate amounts of the two factors were saved, thus leaving the ratio of marginal products constant. Rather, they argued, technical progress had been biased, and likely labor saving (i.e., technical progress saved proportionately more labor). ${ }^{23}$ Under these circumstances (i.e., biased technical progress), the problem is that once an allowance is made in the values of the factor shares for the effect of biased technical progress, the growth accounting estimates become indeterminate in the absence of information about the elasticity of substitution.

22 With the production function $Q=F\left(A_{L} L, A_{K} K\right)$, where $A_{L}$ and $A_{K}$ represent factor-augmenting technical change, the growth of the share of capital is given by (Ferguson 1968): $\left(1-\hat{a}_{t}\right)=[[1-(1-\bar{a})](1-\sigma) / \sigma]\left[\left(\hat{\lambda}_{L}+\hat{L}\right)-\left(\hat{\lambda}_{K}+\hat{K}\right)\right]$ where $(1-\bar{a})=\left[\left(1-a_{0}\right)+\left(1-a_{T}\right)\right] / 2$ is the average share of the initial $\left(1-a_{0}\right)$ and final $\left(1-a_{T}\right)$ periods, $\hat{\lambda}_{L}$ and $\hat{\lambda}_{K}$ are the corresponding growth rates of factor-augmenting technical change, and $\sigma$ is the elasticity of substitution. The degree of bias is given by $B=[(1-\sigma) / \sigma]\left(\hat{\lambda}_{\mathrm{L}}-\hat{\lambda}_{K}\right)$.

23 The issue is not an innocuous point, as Steedman (1985) had proved that Hicks neutrality is an impossibility, an internally inconsistent concept at the level of the economy, in the presence of produced inputs. Steedman (1985) provided several alternative sufficient conditions under which Hicks neutral is impossible. His analysis used the wage-price frontier. This is derived from the relationship $Q=w L+r K$, written as $w=y[1-(r / k)]$, where $y$ is labor productivity and $k$ is capital productivity. The last expression shows that there is a trade-off between wage and profit rates. The sufficiency conditions are stated in terms of the wage-price frontier, e.g., "at least one kind of primary input is paid in advance," or "differential profit rates." 
To obviate this problem, Nelson and Pack (1999) argued that the preferable procedure for constructing $(1-\bar{a})$ in equation (2) is to use the value of capital's share in the terminal period that would have occurred in the absence of technical change. Thus, one should calculate what we refer to as the unobserved constant-technology factor shares. Once this is done, capital's share in the terminal period will be lower, and the growth of TFP will be higher the lower is the elasticity of substitution and the faster the rate of growth of the capital-labor ratio. ${ }^{24}$ Felipe and McCombie (2001) elaborated upon the NelsonPack thesis, and devised an iterative procedure to construct the unobserved constant-technology factor shares by eliminating from the observed factor shares the effect of technical progress. When these new factor shares were used to recalculate TFP growth with Young's (1995) data set, results indicated that for elasticities of substitution below 1, TFP growth in the NIEs was substantially higher than calculated by Young. ${ }^{25}$

\section{WHAT LIES UNDER THE ACCOUNTING IDENTITY PROBLEM?}

The answer to this question should be straightforward by now: it is the nature of the data used, namely, constant-price value (dollars) as opposed to physical quantities (number of widgets). As we have already mentioned, neoclassical production theory should be stated in physical terms, i.e., a production function is a technical relationship among physical quantities (Cobb and Douglas 1928, and Van Beveren 2012, p.100). Researchers, however, use instead value data because firms do not publish physical quantity data (which, by the way, cannot be aggregated into another physical quantity). The implications of using value data, however, have been missed.

In this section, we extend the analysis in section IV, Example 1, and show that this problem does not occur with physical quantities if there were data to estimate econometrically the production function. There is also an accounting identity that links the data in physical terms but this identity does not determine the estimation results. With physical data, a production function regression would pick the true factor elasticities $\alpha$ and $\beta$, which may or may not differ from the factor shares $a$ and $(1-a)$. This is because value data are dependent on factor payments while physical quantities are not. Let's see what happens in this latter case.

Consider a production function in physical terms $Q^{q}=F\left(L, K^{k}, t\right)$, where now $Q^{q}$ and $K^{k}$ are not deflated aggregate values but true physical quantities, units of identical widgets and of machines, respectively, denoted, as before, with the superscripts $q$ and $k$. It can also be written in value terms as $p Q^{q}=p F\left(L, K^{k}, t\right)$, where $p$ is the unit price of output (e.g., dollars/widget). Definitionally, $p Q^{q} \equiv w^{n} L+\rho^{\S} K^{k}$, where $w^{n}$ is the nominal wage rate (dollars/worker) and $\rho^{\$}$ is the rental price of capital (dollars per machine). Then:

$$
Q^{q} \equiv\left(w^{n} / p\right) L+\left(\rho^{\$} / p\right) K^{k}
$$

with units of factor payments now being widgets per worker and widgets per machine, respectively; and output measured in number of widgets. This identity is different from equations above in value terms. Identity (22) is, of course, $Q^{q} \equiv w L+\rho^{q} K^{k}$ (the cost identity in physical terms) discussed in section IV when we discussed Example 1.

24 See also Rodrik (1997) and Young (1998a), who discussed similar issues.

25 It is worth noting that as the constant-technology shares differ from the actual factor shares, the growth accounting equation using the former is not the same as the accounting identity, which uses the latter, and therefore results differ. 
Can the production function be estimated in this case? Yes. To see why, consider $Q^{q}=A_{0} f\left(L, K^{k}\right)$. Partially differentiating $\left(\partial Q^{q}\right) /(\partial L)=f_{L}$ and $\left(\partial Q^{q}\right) /\left(\partial K^{k}\right)=f_{K^{k}}$, with the marginal products both measured in physical units. From Euler's theorem and assuming constant returns to scale, we have: (i) $Q^{q}=f_{L} L+f_{K^{k}} K^{k}$; or, in monetary values (ii) $p Q^{q}=p f_{L} L+p f_{K^{k}} K^{k}$. Assume that marginal products are roughly constant. Regressing $Q^{q}$ on $L$ and $K^{k}$ will provide an estimate of the average values of $f_{L}$ and $f_{K^{k}}$, whether we use (i) or (ii) - we will obtain the marginal products in physical or monetary values, but the latter can always be expressed in terms of the former. Of course, there is no reason why factors should be paid their marginal products, and so a comparison of $p f_{L}$ and $p f_{K^{k}}$ with the actual factor payments would constitute a test of the marginal productivity of factor pricing. Indeed, note that the coefficients of the estimated relationship $p Q^{q}=c L+d K^{k}+u$ are determined by the underlying production function and will differ from the observed wage and price of capital if the factors of production are not paid their marginal products. This is because $Q^{q}$ is a physical measure (as are the marginal products), independent of the distribution of the product.

In the case of the Cobb-Douglas $Q^{q}=A L^{\alpha}\left(K^{k}\right)^{\beta}$ we have $p f_{L}=p\left(\alpha Q^{q} / L\right)$ and $p f_{K^{k}}=p\left(\beta Q^{q} / K^{k}\right)$. If the distribution of output between labor and capital is different from that implied by the marginal productivity conditions, so that the factor shares differ from $\alpha$ and $\beta$, then estimating the production function using physical data will still produce estimates of the output elasticities of labor and capital, that is, $\alpha$ and $\beta$, when they are not constrained to equal unity. ${ }^{26}$

Finally, it is true that some of the recent literature on growth accounting uses firm-level data. This does not mean that the problem is solved as all this work still uses constant-price values and not physical quantities. Indeed, these firm-level studies use deflated sales or value added as a measure of output and total fixed assets for the capital stock. The accounting identity argument remains whether one uses country- or firm-level data, as long as the latter are constant-price values, and not physical quantities. ${ }^{27}$ One could ask whether the difference between using value data and physical quantities is empirically significant. The answer is that it is in general, apart from the already mentioned fact that, conceptually, a production is a relationship among physical quantities. This was shown by Felipe and McCombie (2006, pp.288-95) via simulation, where both the true rate of technical progress and the rate of TFP growth were calculated, the former using physical quantities and the latter by generating prices and then value data.

26 The reader should appreciate that estimating a production function with physical data, is almost impossible due to the large amount of information required (data in physical quantities of all inputs that go into the production process) and the problem of not knowing the specific functional form.

27 There is a new literature on misallocation that has focused on the PRC and India. It uses firm-level data. One example is Bollard, Klenow, and Sharma (2013) on India. This work, however, is based on value added, not physical quantities. Hsieh and Klenow (2009) distinguish between "revenue" and "quantity" TFP. While this work is in the right direction, it is not clear to us, however, that their quantity TFP corresponds to the true physical TFP. This is because Hsieh and Klenow do not have physical quantities of output and "real" output is derived indirectly; and because their measure of the capital stock is not the number of homogeneous machines but the book value of capital stock. 


\section{CONCLUSIONS: WHAT DID WE LEARN FROM (AND WHAT IS LEFT OF) THE DEBATES ABOUT THE SOURCES GROWTH IN EAST ASIA?}

This paper has revisited the literature that originated in the early 1990s on the sources of growth in East Asia, namely, on the contributions of factor accumulation and productivity growth, or "perspiration" versus "inspiration," as Krugman (1994) put it. It became well known because some authors found the low TFP growth results very counterintuitive.

We have argued and shown that the growth accounting exercises and estimations of production functions that underlie all this work are problematic because, by default, they have to use value data as opposed to physical quantities. The problem is not the low TFP growth rates estimated that some researchers found difficult to believe. Rather, the deeper issue is that there is an underlying accounting identity in constant-price value terms that relates definitionally the same variables that appear in the production function. Moreover, aggregate (value-data) TFP is not a measure of productivity. This makes the interpretation of the rate of TFP growth, as if it had been derived from neoclassical production theory with physical terms, incorrect. Likewise, as a consequence of the underlying identity, we have shown that the framework used can never be refuted statistically (regression). We have reviewed five examples in the East Asian literature from the point of view of the accounting identity, and shown the weaknesses of their analyses. Therefore, we deem Krugman's (1994) discussion of the East Asian Miracle far from compelling simply because, as Stiglitz (quoted at the start of the paper) remarked, the total factor productivity debate was much ado about nothing. Our argument would have been the same if TFP growth in East Asia had been much higher. As a matter of logic, the conclusion is that we did not learn much from these exercises.

These somewhat nihilistic conclusions do not mean that nothing was learned about growth in East Asia during the last 25 years, even from the literature that we have criticized. The papers we have surveyed (and many others) contain very interesting case-study accounts of the economies analyzed. Although Asia's growth caught the full attention of economists, it is more difficult to know if this literature ultimately had any lasting impact on growth theory. What we question is the relevance of the growth accounting exercises per se and the discussion of these economies' growth performance in terms of factor accumulation versus TFP growth.

We feel, after a quarter of a century, that the impact of this debate was more akin to a transitory shock than to a permanent effect. ${ }^{28}$ While policy makers across Asia were very much concerned with these results in the 1990s, today they are seen as no more than an academic footnote with little relevance. This was partly the result of the fact that policy makers in East Asia did not see much value in the policy recommendations of this research program; and partly the result of the shift in emphasis away

28 It is true though that these results made it into some development and growth textbooks (Felipe 1999). Fogel (2009), in his analysis of the impact of the Asian miracle on growth theory, seems to indicate that this literature had an impact. It is true that the early endogenous growth papers, those that appeared between 1986 and 1990, were responding mainly to European and US developments between 1950 and 1980. Then theorists shifted some of their focus to Asia during the first half of the 1990s. This is particularly true in discussions about convergence. Our view is that as time passed by, the interest in the Asian miracle declined. 
from the NIEs when growth rates declined significantly after the Asian Financial Crisis of 1997-1998, to the PRC (and to a lesser extent to India). ${ }^{29}$

Some may find it difficult to understand why we question one of the jewels of modern economics, the neoclassical research program on growth and its empirical counterparts, growth accounting, and the econometric estimation of the production function. Our view on this is clear: as we showed in Felipe and McCombie (2013), the hypotheses that this model generates are "Not Even Wrong" because they cannot be tested and potentially refuted. The neoclassical growth model is a virtual construct, based on two unstable pillars: first, a group of concepts and variables that are fictional, a humbug, such as the aggregate production function $Q=A F(K, L)$, the aggregate capital stock, or the idea of aggregate technology or productivity; and second, the artificial accounting identity $Q \equiv w L+r K$ in value terms (dollars), which splits the NIPA's operating surplus into a putative price $(r$ or $\rho$ ) and a putative quantity $(K)$. This identity contains the same variables as the aggregate production function (output, labor and capital stock) and can be easily rewritten as a specific form of it (e.g., Cobb-Douglas, CES, translog). This explains why aggregate production functions appear to work empirically (i.e., fit real data well) when all they do is to mimic the identity. Naturally, this gives the illusion that we know a lot about development and about the determinants of income differences (Hsieh and Klenow 2010). On the contrary, our view is that this framework cannot be used for development accounting, and what is commonly termed as total factor productivity is not the key to understand development because it is not a measure of productivity.

The growth literature has to move beyond the framework of the neoclassical model and the TFP research program to analyze how economies grow, and there are signs that this is underway, e.g., the work on structural change by Hidalgo et al. (2007) and Hidalgo and Hausmann (2009) (see Felipe et al. 2012 for an application). East Asia grew (and continues growing) as a result of the accumulation of many capabilities. This was a slow and painstaking process that happened in the context of the export-led growth model and the industrialization drive of the region during the 1960s-1990s, which underpin its fast structural change.

29 This was in the context of being the largest driver of world growth during the last 15 years (see, for example, Rodrik and Subramanian 2004, Bosworth and Collins 2007, Perkins 2015, Lin and Zhang 2015). Methodologically, these papers did not do anything new, however. The PRC's growth rate also started declining after 2008-2009, partly as a result of the Great Financial Crisis and partly as a result of its own internal dynamics (Asian Development Bank 2016). This has led Pritchett and Summers (2013) to speak of an Asiaphoria and predict that the region's growth rates will have to decline because the evidence suggests that growth rates show little statistical persistence, i.e., there is regression to the mean; and Asia's growth rates have for a long time been over two standard deviations of the historical growth mean. This cannot last. Note that Pritchett and Summers' arguments are very different from those of Krugman (1994). 


\section{APPENDIX: THE ACCOUNTING IDENTITY}

\section{The Isomorphism between the Accounting Identity in Value Terms and the "Value Production Function"}

To complete our argument in section III why using value data is problematic, suppose that the data for the economy in question show that factor shares are constant, i.e., $a_{t} \equiv W_{t} / Q_{t}=a$ and $\left(1-a_{t}\right) \equiv O S_{t} / Q_{t}=(1-a)$, and also that $\hat{\lambda}_{t} \equiv a_{t} \hat{w}_{t}+\left(1-a_{t}\right) \hat{r}_{t} \equiv \hat{\lambda}$, i.e., $\hat{\lambda}_{t}$ happens to grow at a constant rate. Given the discussion above, it is clear that the argument does not depend on these two assumptions about the data. Then the identity (6) becomes $\hat{Q}_{t} \equiv a \hat{w}+(1-a) \hat{r}+a \hat{L}_{t}+(1-a) \hat{K}_{t} \equiv \hat{\lambda}+a \hat{L}_{t}+(1-a) \hat{K}_{t}$, which upon integration gives:

$$
Q_{t} \equiv A \exp (\hat{\lambda} t) L_{t}^{a} K_{t}^{(1-a)}
$$

with $A \equiv(a)^{-a}(1-a)^{-(1-a)}$. The reader will appreciate that expression (A1) is the original accounting identity equations (4)-(5) rewritten in a different but equivalent form, something that could be misinterpreted as an aggregate Cobb-Douglas production function. It must be emphasized that this derivation involves only the transformation of an accounting identity. ${ }^{30}$ There is no reference to production functions, returns to scale, marginal productivities, competitive equilibrium conditions or to any economic theory of production.

What does the derivation of the identity in "Cobb-Douglas form" imply? Suppose someone estimates econometrically $Q_{t}=A \exp (\hat{\lambda} t) L_{t}^{\alpha} K_{t}^{\beta} \exp \left(u_{t}\right)$ and the data show that factor shares are constant [i.e., $a_{t}=a$ and consequently $\left(1-a_{t}\right)=(1-a)$ ], and also that $\hat{\lambda}_{t}=\hat{\lambda}$. It should be obvious that the expression estimated is the identity (A1), that there is no error term and therefore the fit will be perfect, and that the estimated elasticities will equal the factor shares, i.e., $a=\alpha$ and $(1-a)=\beta .{ }^{31}$ This result is driven by the accounting identity. What would be the point of this exercise?

Naturally, if the data do not follow the paths above, i.e., if $a_{t} \neq a$ [and consequently $\left.\left(1-a_{t}\right) \neq(1-a)\right]$ and $\hat{\lambda}_{t} \neq \hat{\lambda}$, then $Q_{t}=A \exp (\hat{\lambda} t) L_{t}^{\alpha} K_{t}^{\beta} \exp \left(u_{t}\right)$ will not be a good approximation to the identity and it, once again, will give the impression that one is estimating a true economic relationship. However, this is not the case and it cannot be interpreted as providing any evidence that one is estimating a production function. All that is needed is to substitute the actual paths for the factor shares $a_{t}$ and $\left(1-a_{t}\right)$ and for $\hat{\lambda}_{t} \equiv a_{t} \hat{w}_{t}+\left(1-a_{t}\right) \hat{r}_{t}$ back into the identity $\hat{Q}_{t} \equiv a_{t} \hat{w}_{t}+\left(1-a_{t}\right) \hat{r}_{t}+a_{t} \hat{L}_{t}+\left(1-a_{t}\right) \hat{K}_{t}$. Note, for example, that $\hat{\lambda}_{t}$ is a growth rate that varies cyclically and hence the constant $\hat{\lambda}$ would not be a good proxy. It is more likely that a trigonometric functional form would give a better statistical fit (see Felipe and McCombie 2011 for an example). Nothing in neoclassical production theory says that technical progress has to grow at a constant rate with a random fluctuation. If factor shares vary, we will also need a functional form that better approximates their path (as Kim and Lau 1994 did, which we discussed in section IV).

30 Fisher (1971) showed using simulation analysis that if factor shares are constant (if they are) it is not because the economy's technology is Cobb-Douglas. Rather, it is the other way around, that is, the Cobb-Douglas form works empirically (when it does) because factor shares happen to be constant (if they are). The latter could be simply due to the fact that firms use a constant markup on unit labor costs to set prices.

31 Strictly speaking, perfect multicollinearity will mean that the coefficients cannot be estimated with precision. 
In other words and summing up, it is always possible to rewrite the identity $Q_{t} \equiv W_{t}+O S_{t} \equiv w_{t} L_{t}+r_{t} K_{t}$ as a particular form of $Q_{t}=A_{t} F\left(K_{t}, L_{t}\right)$, or $Q=F\left(A_{L} L, A_{K} K\right)$. Young's growth accounting equation, Kim-Lau's regression, and Barro-Hsieh's identity cannot be distinguished from each other (this is not an identification problem because one of the equations is an identity) because they all use (constant-price) value data and, effectively, are the same. The implication for all this work is that it is the income accounting identity that drives the results. 


\section{REFERENCES}

Asian Development Bank. 2013. Asia's Economic Transformation: Where to, How, and How Fast? Key Indicators for Asia and the Pacific 2013 Special Chapter. Manila.

2016. Asia's Potential Growth. Asian Development Outlook 2016. Special Chapter. Manila.

Barro, Robert. 1999. “Notes on Growth Accounting.” Journal of Economic Growth 4 (2): 119-37.

Bollard Albert, Peter J. Klenow, and Gunjan Sharma. 2013. “India's Mysterious Manufacturing Miracle.” Review of Economic Dynamics 16 (1): 59-85.

Bosworth, Barry, and Susan Collins. 2007. "Accounting for Growth: Comparing China and India." NBER Working Paper No. 12943.

Cobb, Charles, and Paul Douglas. 1928. "A Theory of Production.” The American Economic Review 18 (1): 139-65.

Chow, Gregory. 1993. "Capital Formation and Economic Growth in China." The Quarterly Journal of Economics 108 (3): 809-42.

Collins, Susan, and Barry Bosworth. 1996. "Economic Growth in East Asia: Accumulation versus Assimilation.” Brookings Papers in Economic Activity 1996 (2): 135-203.

Felipe, Jesus. 1999. "Total Factor Productivity Growth in Asia: A Critical Survey." The Journal of Development Studies 35 (4): 1-41.

Felipe, Jesus, and Franklin M. Fisher. 2003. "Aggregation in Production Functions: What Applied Economists Should Know.” Metroeconomica 54 (2-3): 208-62.

Felipe, Jesus, Utsav Kumar, Arnelyn Abdon, Marife Bacate. 2012. "Product Complexity and Economic Development." Structural Change and Economic Dynamics 23 (1): 36-68.

Felipe, Jesus, and John S. L. McCombie. 2001. "Biased Technical Change, Growth Accounting and the Conundrum of the East Asian Miracle." Journal of Comparative Economics 29 (3): 542-65.

- 2006. "The Tyranny of the Identity: Growth Accounting Revisited." International Review of Applied Economics 20 (3): 283-99.

- 2011. "Some Caveats Modeling Technical Progress and Investment: The Case of China." Journal of International Commerce, Economics and Policy 2 (2): 305-24.

2013. The Aggregate Production Function and the Measurement of Technical Change: 'Not Even Wrong'. Edward Elgar Publishing.

Ferguson, Charles Elmo. 1968. "Neoclassical Theory of Technical Progress and Relative Factor Shares." Southern Economic Journal 34 (4): 490-504. 
Fernald, John, and Brent Neiman. 2011. "Growth Accounting with Misallocation: Or, Doing Less with More in Singapore." American Economic Journal: Macroeconomics 3 (2): 29-74.

Fischer, Stanley. 1993. “The Role of Macroeconomic Factors in Growth.” Journal of Monetary Economics 32 (3): 485-512.

Fisher, Franklin M. 1971. "Aggregate Production Functions and the Explanation of Wages: A Simulation Experiment." The Review of Economics and Statistics 53 (4): 305-25.

Fogel, Robert W. 2009. "The Impact of the Asian Miracle on the Theory of Economic Growth." NBER Working Paper 14967.

Hall, Robert E. 1988. "The Relation between Price and Marginal Cost in U.S. Industry." Journal of Political Economy 96 (5): 921-47.

Hall, Robert E. 1990. "Invariance Properties of Solow's Productivity Residual." In Growth/Productivity/Employment: Essays to Celebrate Bob Solow's Birthday, edited by Peter Diamond, chapter 5, 71-112. Cambridge, MA: MIT Press.

Hall, Robert E., and Dale W. Jorgenson. 1967. "Tax Policy and Investment Behavior." The American Economic Review 57 (3): 391-414.

Hidalgo, Cesar A., and Ricardo Hausmann. 2009. "The Building Blocks of Economic Complexity." Proceedings of the National Academy of Sciences 106 (26): 10570-75.

Hidalgo, Cesar A., Bailey Klinger, Albert-László Barabási, and Ricardo Hausmann. 2007. "The Product Space Conditions the Development of Nations." Science 317 (5837): 482-87.

Hsieh, Chang-Tai. 1999. "Productivity Growth and Factor Prices in East Asia." The American Economic Review 89 (2): 133-38.

2002. "What Explains the Industrial Revolution in East Asia? Evidence from Factor Markets." The American Economic Review 92 (3): 502-26.

Hsieh, Chang-Tai, and Peter J. Klenow. 2009. "Misallocation and Manufacturing TFP in China and India.” The Quarterly Journal of Economics 124 (4): 1403-48.

Hsieh, Chang-Tai, and Peter J. Klenow. 2010. "Development Accounting." American Economic Journal: Macroeconomics 2 (1): 207-23.

Jorgenson, Dale W., and Zvi Griliches. 1967. "The Explanation of Productivity Growth." The Review of Economic Studies 34 (3): 249-83.

Kee, Hiau Looi. 2002. "Markups, Returns to Scale, and Productivity: A Case Study of Singapore's Manufacturing Sector.” World Bank Working Paper 2857.

Kim, Jong-II, and Lawrence J. Lau. 1994. "The Sources of Economic Growth of the East Asian Newly Industrialized Countries." Journal of the Japanese and International Economies 8 (3): 235-71. 
Klenow, Peter J., and Andrés Rodríguez-Clare. 1997. "The Neoclassical Revival in Growth Economics: Has it gone too far?” NBER Macroeconomics Annual 12: 73-114.

Krugman, Paul. 1992. "Comment to Alwyn Young's 'A Tale of Two Cities: Factor Accumulation and Technical Progress in Singapore and Hong Kong.”' NBER Macroeconomics Annual 7: 54-56.

1994. "The Myth of Asia's Miracle." Foreign Affairs 73 (6): 62-78.

Lin, Justin Yifu, and Fan Zhang. 2015. "Sustainable Growth of the People's Republic of China." Asian Development Review 32 (1): 31-48.

Nadiri, M. Ishaq. 1970. "Some Approaches to the Theory and Measurement of Total Factor Productivity: A Survey." Journal of Economic Literature 8 (4): 1137-77.

Nelson, Richard. 1973. “Recent Exercises in Growth Accounting: New Understanding or Dead End.” The American Economic Review 63 (3): 462-68.

Nelson, Richard, and Howard Pack. 1999. "The Asian Growth Miracle and Modern Growth Theory." The Economic Journal 109 (457): 416-36.

Perkins, Dwight H. 2015. "Understanding the Slowing Growth Rate of the People's Republic of China." Asian Development Review 32 (1): 1-30.

Pritchett, Lant, and Lawrence H. Summers. 2013. “Asiaphoria Meets Regression to the Mean.” 2013 Asia Economic Policy Conference: Prospects for Asia and the Global Economy. Federal Reserve Bank of San Francisco.

Rashid, Salim. 2000. Economic Policy for Growth. Economic Policy is Human Development. Kluwer Academic Publishers.

Robertson, Peter. 2000. "Diminishing Returns? Growth and Investment in East Asia." Economic Record 76 (235): 343-53.

Rodrik, Dani. 1997. "TFPG Controversies, Institutions, and Economic Performance in East Asia." NBER Working Paper No. 5914.

Rodrik, Dani, and Arvind Subramanian. 2004. "Why India Can Grow at 7 Percent a Year or More: Projections and Reflections." IMF Working Paper WP/04/118.

Simon, Herbert. 1979a. "On Parsimonious Explanations of Production Relations." The Scandinavian Journal of Economics 81 (4): 459-71.

Simon, Herbert. 1979b. "Rational Decision Making in Business Organizations." The American Economic Review 69 (4): 493-513.

Solow, Robert. 1956. "A Contribution to the Theory of Economic Growth.” The Quarterly Journal of Economics 70 (1): 65-94. 
1957. "Technical Change and the Aggregate Production Function." The Review of Economics and Statistics 39 (3): 312-20.

Steedman, Ian. 1985. "On the 'Impossibility' of Hicks-Neutral Technical Change.” The Economic Journal 95 (379): 746-58.

Stiglitz, Joseph. 2001. "From Miracle to Crisis to Recovery: Lessons from Four Decades of East Asian Experience." In Rethinking the East Asian Miracle, edited by Joseph E. Stiglitz and Shahid Yusuf, 509-26. Oxford University Press.

Van Beveren, Ilke. 2012. "Total Factor Productivity Estimation: A Practical Review." Journal of Economic Surveys 26 (1): 98-128.

Wilson, Daniel J. 2009. "IT and Beyond: The Contribution of Heterogeneous Capital to Productivity." Journal of Business and Economic Statistics 27 (1): 52-70.

Wong, Fot-Chyi, and Wee-Beng Gan. 1994. "Total Factor Productivity Growth in the Singapore Manufacturing Industries during the 1980's." Journal of Asian Economics 5 (2): 177-96.

Young, Alwyn. 1992. "A Tale of Two Cities: Factor Accumulation and Technical Change in Hong Kong and Singapore." NBER Macroeconomics Annual 7: 13-54.

1994. "Lessons from the East Asian NICs: A Contrarian View." European Economic Review 38 (3-4): 964-73.

1995. "The Tyranny of the Numbers: Confronting the Statistical Realities of the East Asian Growth Experience.” The Quarterly Journal of Economics 110 (3): 641-80.

- 1998a. "Paasche vs. Laspeyres: The Elasticity of Substitution and Bias in the Measures of TFP Growth.” NBER Working Paper No. 6663.

1998b. "Alternative Estimates of Productivity Growth in the NICs: A Comment on the Findings of Chang-Tai Hsieh.” NBER Working Paper No. 6657. 


\section{The Debate about the Sources of Growth in East Asia after a Quarter of a Century: much ado about nothing}

We revisit the lively debate about the sources of growth in East Asia of the 1990s, generated by the wellknown papers by Alwyn Young and Paul Krugman. We show that the methodologies used to apportion growth were problematic, with the consequence that the debate was much ado about nothing.

\section{About the Asian Development Bank}

ADB's vision is an Asia and Pacific region free of poverty. Its mission is to help its developing member countries reduce poverty and improve the quality of life of their people. Despite the region's many successes, it remains home to a large share of the world's poor. ADB is committed to reducing poverty through inclusive economic growth, environmentally sustainable growth, and regional integration.

Based in Manila, ADB is owned by 67 members, including 48 from the region. Its main instruments for helping its developing member countries are policy dialogue, loans, equity investments, guarantees, grants, and technical assistance. 